\title{
Development of lightweight strain hardening cementitious composite for structural retrofit and energy efficiency improvement of unreinforced masonry housings
}

\author{
Honggang Zhu ${ }^{\mathrm{a}}$, Kai Tai Wan ${ }^{\mathrm{b}, *}$, Elnara Satekenova ${ }^{\mathrm{c}}$, Dichuan Zhang ${ }^{\mathrm{c}}$, \\ Christopher K.Y. Leung ${ }^{\mathrm{d}}$, Jong Kim ${ }^{\mathrm{c}}$ \\ ${ }^{a}$ Nano and Advanced Materials Institute Limited, Hong Kong \\ ${ }^{b}$ Department of Civil and Environmental Engineering, Brunel University London, UK \\ ${ }^{c}$ Department of Civil Engineering, Nazarbayev University, Kazakhstan \\ ${ }^{d}$ Department of Civil and Environmental Engineering, The Hong Kong University of \\ Science and Technology, Hong Kong
}

\begin{abstract}
The thermal, mechanical and durability properties of lightweight strain hardening cementitious composite (LSHCC) as well as the effectiveness of using LSHCC for structural retrofitting of unreinforced masonry (URM) wall is reported in this study. The proper range of water content, dosage of superplasticiser and viscosity modifying agent was explored from the survivability test of glass micro hollow bubble (3M-S15), which was much more fragile but effective in reducing the thermal conductivity of the composite than other studies. Then, the tensile properties of LSHCC with wet density of about $1,300-1,400 \mathrm{~kg} / \mathrm{m}^{3}$ from different proportion of replacement of ordinary Portland cement (OPC) by fly ash (FA) and ground granulated blast-furnace slag (GGBS) as well as different volume fraction of polyvinyl alcohol (PVA) fibre
\end{abstract}

*Email: KaiTai.Wan@brunel.ac.uk 
were measured. The tensile ductility of LSHCC of replacement by FA was in general better than pure OPC or with GGBS blends. The tensile strength and ductility of LSHCC with $1.75 \%$ volume fraction of PVA fibre was about $3 \mathrm{MPa}$ and 2-4\%, respectively. The compressive strength ranged from 14 to $31 \mathrm{MPa}$. The thermal conductivity of selected LSHCC ranged from 0.34 to $0.51 \mathrm{~W} / \mathrm{m} \cdot \mathrm{K}$. The coefficient of water permeability of LSHCC was comparable with reference normal concrete and the ECC-M45 in the literature. The coefficient of chloride diffusivity of most LSHCC in this study was lower than the reference concrete because of the chloride binding of FA and GGBS. However, the carbonation rate of the LSHCC was generally higher. Three sets of LSHCC with similar tensile strength but different ductility were chosen for the evaluation of the effectiveness on structural retrofitting of an unreinforced masonry wall by in-plane and out-of-plane pushover analysis. The parameters of a finite element model with smeared crack material model was tuned based on the stress-strain relationship of LSHCC measured from the tensile tests in this study. There was no improvement of using LSHCC with $0.6 \%$ tensile ductility. By applying a $10 \mathrm{~mm}$ thick $\mathrm{LSHCC}$ with $2.2 \%$ and $4.4 \%$ tensile ductility on each side of an URM wall, the ductility of the retrofitted wall under in-plane loading was increased by $38 \%$ and $72 \%$, respectively while it was increased by $164 \%$ of both kinds of LSHCC for out-of-plane loading. Keywords:

lightweight strain hardening cementitious composites, hollow glass bubble, tensile ductility, thermal conductivity, pushover analysis, smeared crack material model 


\section{Introduction}

Unreinforced masonry (URM) housings are vulnerable to lateral loadings such as seismic action [29, 23, 11] and wind pressure [17]. Although it is prohibited or strictly controlled to build new URM housings in many seismic regions, it is necessary to preserve the surviving/existing URM housing stock, especially some of which are historic. Confined masonry (CM) wall as an infill of reinforced concrete frame is common in low to medium height residential buildings. It can provide in-plane ductility under seismic [12, 27], however, out-of-plane collapse is still critical of old existing buildings, which were not with proper dimensioning and detailing required in modern seismic design codes $[24,53]$. The collapse of confined masonry wall makes the housings no longer serviceable and may cause serious damage to adjacent structures. There are different methods to retrofit existing URM and CM housings such as base isolation [34, 49], fibre reinforced polymer (FRP) fabric, tow sheets and tapes with Kevlar and carbon fibre [22], near surface mounted (NSM) glass FRP bars [19] and carbon FRP strips [16] as well as textile reinforced mortar (TRM) with carbon fibre fabric [48, 47]. Albeit the base isolation technique is effective, it causes disturbance to the current occupant and the cost is justifiable only for valuable heritage. The drawbacks of using FRP fabric to retrofit masonry wall are the incompatibility of the polymeric matrix to common rendering/plastering materials and the low tolerance to uneven surface. The NSM FRP reinforcement retrofitting technique can resolve the stated drawbacks of FRP fabric and improve the ductility of URM and CM wall under in-plane and out-of-plane loadings, but it is labour intensive and not as effective as FRP fabric and TRM. TRM with carbon fibre fabric is a 
promising technique, however, the stiffness of high performance man-made fibre is much higher than the wall so the failure mode may be interlaminate shear failure that is sudden and brittle.

Strain hardening cementitious composite (SHCC), which is referred as engineered cementitious composite (ECC) or pseudo ductile cementitious composite (PDCC) in some literature, is a family of high performance fibre reinforced cementitious composite [32] based on micromechanical analytical tools $[42,33,38]$. The key characteristic of SHCC is its high tensile ductility. The matrix can be replaced by other inorganic material such as fly ash based geopolymer $[45,13,44]$ and other functionalities such as lightweight [54, 32, 26, 28], self-healing [3, 37, 59], low-shrinkage [13], water-repelling [57] and self-sensing [1, 51]. URM wall strengthened by SHCC with hybrid steel and polyethylene fibre was proved to improve the load capacity as well as ductility under quasi-static and dynamic loading [40]. Commercial SHCC shotcrete with polyvinyl alcohol (PVA) fibre could improve both the in-plane [36] and out-of-plane [35] load capacity of URM wall. Semi empirical-analytical design formulas were proposed, however, those formulas, which considered the tensile strength of SHCC but not the ductility, consistently underestimated the load capacity of the strengthened URM walls from experiments.

In addition to structural retrofit of existing URM and CM walls, it is desirable to improve the energy efficiency by enhancing the thermal insulation of the strengthening materials. In a study about the energy performance of housing in south-eastern Europe, the specific heat loss through the typical masonry walls is about $40 \%$ of the total heat loss through the entire building 
envelope [41]. In another study, the energy requirement of heating of typical historic stone masonry housings in Italy was reduced by half and about $15 \%$ by adding $1.5 \mathrm{~cm}$ thick traditional gypsum panel (density $1000 \mathrm{~kg} / \mathrm{m}^{3}$ and thermal conductivity $0.4 \mathrm{~W} / \mathrm{m} \cdot \mathrm{K}$ ) and plastering with glass bubble (unknown thickness, density $450 \mathrm{~kg} / \mathrm{m}^{3}$ and thermal conductivity $0.122 \mathrm{~W} / \mathrm{m} \cdot \mathrm{K}$ ), respectively [7].

The wet density of conventional SHCC is about $2,000 \mathrm{~kg} / \mathrm{m}^{3}$ and the thermal conductivity is about $1.2-1.5 \mathrm{~W} / \mathrm{m} \cdot \mathrm{K}$ [56]. There are a few studies about lightweight SHCC (LSHCC) to enhance the thermal resistance by using presoaked expanded perlite aggregate $\left(1,800-1,900 \mathrm{~kg} / \mathrm{m}^{3}\right)[28,43]$ and fly ash cenospheres $\left(1,600-1,800 \mathrm{~kg} / \mathrm{m}^{3}\right)$ [26]. [54, 32] explored four different methods to reduce the density of SHCC with PVA fibre, (i) air-entrainment admixture, (ii) polymeric micro-hollow bubble, (iii) natural lightweight perlite and (iv) glass micro-hollow bubble (GB) and concluded that GB demonstrated superior mechanical properties than the other three approaches. [43] compared the lightweight strain hardening geopolymeric composite with $2 \%$ volume fraction of PVA fibre as well as expanded recycled glass (EG) and microscopic hollow ceramic spheres (MS). The performance of the lightweight composite is summarised in Table 1 while the properties of the two types of GB (3M-S38 and 3M-S60), EG and MS are shown in Table 4. High mass fraction of the lightweight aggregates increases the cost of LSHCC significantly. Another expensive component of LSHCC is the PVA fibre.

In this study, LSHCC with low mass fraction ( $~ 5 \%$ to total of cementitious materials and sand filler) of GB and lower volume fraction of PVA fibre (1.5-1.75\%) was developed. In additional to physical (density and flow 
diameter) and mechanical (tensile strength, tensile ductility and compressive strength) properties of LSHCC, other performance indicators of thermal insulation (thermal conductivity) and durability (water permeability, chloride ion diffusivity and carbonation rate) will also be reported. The applicability of the developed LSHCC for structural retrofitting of masonry wall will be verified based on pushover nonlinear analysis through computer simulation.

\section{Materials}

The materials used in this study for preparing the cementitious matrix of LSHCC are ordinary Portland cement (OPC, CEM I 52.5), fly ash (FA, from CLP Group, Hong Kong) and ground granulated blast-furnace slag (GGBS, from K-Wah Construction Materials Ltd, Hong Kong). The specific gravity of OPC, FA and GGBS is 3.1, 2.3 and 2.95, respectively. The results of chemical composition of OPC, FA and GGBS by X-ray fluorescence (XRF) spectroscopy (JEOL JSX-3201Z) are shown in Table 2. The sand used in this study was Class D (between $180 \mu \mathrm{m}$ and $270 \mu \mathrm{m}$ ) standard silica sand [8].

High range polycarboxylate based superplasticiser (SP, BASF Glenium ACE 80, the solid content of which is about 32\%) was used. Industrial grade hydroxypropyl methylcellulose (HPMC) was used as viscosity modifying agent to control segregation and bleeding of the wet mix before addition of fibre.

Short PVA fibre (Kuraray Co. Ltd, Japan) was used to reinforce cementitious matrix to achieve strain hardening property of the composite. It consists of $1.2 \%$ mass of oil coating on the surface to reduce the chemical 
bonding with the cementitious matrix. The properties of PVA fibre are listed in Table 3.

The physical, mechanical and thermal properties of the commercially available GB from 3M used in this study, which is referred as $\mathrm{S} 15$ onwards, are shown in Table 4. In order to reduce the mass fraction of LSHCC, GB with larger diameter but thinner wall is used. The mean diameter of S15 is $55 \mu \mathrm{m}$, while the diameters of the 10th percentile, 90th percentile and effective top size given by the manufacturer are 25, 90 and $95 \mu \mathrm{m}$, respectively. The thermal conductivity of $\mathrm{S} 15$ is only $0.055 \mathrm{~W} / \mathrm{m} \cdot \mathrm{K}$, which is $51.2 \%, 72.5 \%$ and $45 \%$ lower than S38, S60 and MS, respectively. However, the crush strength of S15 is $2.1 \mathrm{MPa}$, which is only $7.2 \%, 3.0 \%, 4.7 \%$ of S38, S60 and MS, respectively in the previous studies [54,32,43]. It is potentially to make LSHCC with similar thermal insulation by using much less GB in the matrix.

\section{Experiment programme}

Since the crush strength of S15 is much lower than the lightweight aggregates used in [54,32, 43], it is critical to minimise the damage of S15 during mixing to maintain the excellent thermal resistance. The experimental programme was divided into three stages. The first stage was to determine appropriate range of water content, dosage of SP and HPMC as well as mixing time/speed of mortar, which consisted of OPC, sand and S15 only without PVA fibre. The damage of S15 during mixing was indicated by the excessive measured wet density compared with estimated value based on the density of all ingredients and mix proportion. The second stage was to prepare LSHCC samples, based on the findings about the appropriate range of water content, 
SP and HPMC dosage from stage one, with replacement of OPC by FA and GGBS and different volume fraction of PVA fibre (from 1.5\% to 2\%) for direct tensile test to measure the tensile properties of the composite. The target wet density of LSHCC is about $1,350 \mathrm{~kg} / \mathrm{m}^{3}$. The third stage was to examine the compressive strength, thermal conductivity and other durability parameters including water permeability, chloride diffusion and carbonation rate of selected sets of LSHCC from stage 2.

\subsection{Stage 1: Mixing and GB survivability test}

Table 5 shows the 22 sets of the GB survivability test in 6 groups with different water content (from $261 \mathrm{~kg} / \mathrm{m}^{3}$ to $353 \mathrm{~kg} / \mathrm{m}^{3}$ ) to achieve similar consistency, which was indicated by flow diameter, by varying water content, SP and HPMC dosage. The water content of group A was minimum with maximum dosage of SP and vice versa in group F. The amount of S15 in all mixes was fixed at 10\% mass to cement content. However, the estimated wet density varied for different groups because of different water content. For group D with water content $316 \mathrm{~kg} / \mathrm{m}^{3}$, the SP dosage (solid content) was decreased from $0.63 \%$ to $0.1 \%$ mass to the cement content. The dosage of HPMC varied from zero to $0.188 \%$ mass to the cement content.

All dry ingredient was dry-mixed in the Hobart Mixer HSM 20 for 7 minutes at the lowest speed (speed 1). The time of wet mixing varied from 8 to 18 minutes. The mixing speed of wet mixing was at the lowest speed except A2 and A3, which was set at medium speed (speed 2). After the wet mixing, the fresh mix was poured into $100 \mathrm{~mm}$ cubic steel mould and compacted on a vibrating table. After wiping any excess outside the mould, it was weighted in an electronic balance with $\pm 5 \mathrm{~g}$ accuracy. The reported plastic density 
was the average of three samples from the same batch of mix.

The consistency of the fresh mortar was measured according to modified flow table test from BS EN 1015-3:1999 [9]. The modification was to skip the vibration after compaction and mould raising. The flow diameter was measured 2 times of each test with accuracy up to $\pm 1 \mathrm{~mm}$. The diameter reported was the range of flow diameters from 3 repeated tests and rounded to $5 \mathrm{~mm}$.

\subsection{Stage 2: Mixing, curing and testing of LSHCC}

The specimens of LSHCC for direct tensile test were divided into 3 groups (Table 6). All mixes consisted of about 30\% volume fraction of S15. The targeted wet density was about $1,350 \mathrm{~kg} / \mathrm{m}^{3}$. Group 1 (GI) consisted of OPC, S15 and sand. Group 2 (GII) consisted of OPC, FA, S15 and sand. Group 3 (GIII) consisted of OPC, FA, GGBS, S15 and sand. OPC, FA, GGBS, S15, sand, HPMC, if applicable, was mixed in Hobart Mixer HSM 20 at the lowest speed for 7 minutes. SP was mixed with water and the mixture was then added to the dry mix and mixed at the lowest speed for another 9 minutes. PVA fibre was added and mixed for further 5 minutes at the lowest speed to form LSHCC. The wet density and consistency of fresh LSHCC was measured by the same method in section 3.1.

In addition to fresh properties of LSHCC, tensile test samples were prepared. The dimensions of the plate-shape specimen for direct tensile test of LSHCC were $350 \mathrm{~mm} \times 50 \mathrm{~mm} \times 15 \mathrm{~mm}$ (Figure 1). 3 specimens were prepared of each mix. The specimens were covered by cling wrap at room temperature after casting. Then, they were demoulded and cured at $25^{\circ} \mathrm{C}$ and $98 \%$ relative humidity for 27 days. After 28 days from casting, the specimens were 
air dried for 1 day. In order to strengthen the region of the specimen under high gripping force during test and prevent cracks form in that region, a layer of carbon fibre reinforced polymer (CFRP) composite $(100 \mathrm{~mm} \times 50 \mathrm{~mm})$ was glued by epoxy on both ends of one of the surface and a $1.2 \mathrm{~mm}$ thick aluminium sheet $(70 \mathrm{~mm} \times 50 \mathrm{~mm})$ was attached on top of each CFRP sheet. After the resin of CFRP was cured for 24 hours at room temperature, the same procedure was repeated to the other surface of the specimen. The tensile test was performed between the 31st and 35th day from casting. The tensile test was carried in MTS 810. During the test, a pair of liner variable differential transformers (LVDTs) were mounted at the edge of the surface of carbon fibre layer. At the other end of the LVDT, a pair of fixed plates with an adjustable screw were glued on the side of the specimen by 2-part araldite epoxy adhesive. The loading rate was set at $0.1 \mathrm{~mm} / \mathrm{min}$.

\subsection{Stage 3: Compressive strength, thermal and durability tests of LSHCC}

Compressive strength, thermal conductivity, water permeability, chloride diffusivity and carbonation rate of LSHCC was tested only on selected mixes but from different batch of mixing followed the identical mixing procedure described before. Three $100 \mathrm{~mm}$ cubic samples were prepared for compression test and they were covered by cling wrap for 24 hours in the room temperature (about $23 \pm 1^{\circ} \mathrm{C}$ ) of laboratory after casting. Then, the cubic samples were demoulded and cured at $25^{\circ} \mathrm{C}$ and $98 \%$ R.H. for further 27 days. The cubic samples were tested in ELE automatic compression machine with loadcontrol at $3 \mathrm{kN} / \mathrm{s}$ loading rate. The reported compressive strength was the average of three samples from the same batch.

The coefficient of thermal conductivity was measured by hot-wired method 
(QTM-500, Kyoto Electronic). A $100 \mathrm{~mm}$ cubic sample was prepared followed with the same curing procedures described for compressive strength test. After curing, the sample was oven-dried at $115^{\circ} \mathrm{C}$ for 24 hours and then cooled down to room temperature for another 24 hours. The reported coefficient of thermal conductivity was the average of three measurements from three different faces of the same cubic sample.

The coefficient of water permeability was measured by modified falling head test [31]. The dimensions of the sample were $130 \mathrm{~mm} \times 50 \mathrm{~mm} \times 15 \mathrm{~mm}$. The samples were cured in the room temperature in laboratory for 28 days before the test. The water reservoir was made of poly(methyl methacrylate) (PMMA) and all edges were sealed by epoxy (Figure 2). The internal dimensions of the water reservoir were $120 \mathrm{~mm} \times 40 \mathrm{~mm}$. The top and bottom chambers were filled by water and the measurement was started after 2 weeks so that the sample was saturated. The top of the standpipe was covered by cling wrap to minimise water loss during the test. The water head was measured twice a week for 4 weeks. The coefficient of water permeability $(k)$ can be estimated from the linear fit of the plot of natural logarithm of the ratio of initial to final water head versus time according to the Darcy's law in Eq. (1).

$$
k=\frac{a \cdot d}{A \cdot t_{f}} \ln \frac{h_{i}}{h_{f}}
$$

where $a, A, d, t_{f}, h_{i}$ and $h_{f}$ are the area of the standpipe, the area of the reservoir, thickness of the specimen, time taken, initial water head and final water head, respectively. The reported coefficient of water permeability is the average of three specimens from the same batch of mix. 
The coefficient of chloride diffusivity was estimated by the hybrid of nonsteady state migration test and colorimetric method $[5,6]$. Cylindrical specimens with dimensions of $100 \mathrm{~mm}$ diameter and $50 \mathrm{~mm}$ thick were prepared for non-steady state migration test. The specimens were cured at the room temperature of laboratory environment for 28 days. The circumferential surface was sealed by epoxy and vacuum saturated in water. The upstream and downstream reservoir was filled by $3 \%$ mass of sodium chloride solution and $0.1 \mathrm{~N}$ sodium hydroxide solution, respectively. A \#30 copper mesh was attached on each flat surface of the cylindrical sample and they were connected with $30 \mathrm{~V}$ direct current (Figure 3). After 48 hours, the specimen was split into 2 halves to reveal the fresh surface. The depth of chloride penetration $\left(x_{d}\right)$ was measured from the colour change by spraying $0.1 \mathrm{~N}$ silver nitrite $\left(\mathrm{AgNO}_{3}\right)$ aqueous solution, at which the free chloride amount $\left(30.5 \mathrm{~mol} / \mathrm{m}^{3}=0.03 \mathrm{~N}\right)$ at the colour-change boundary was similar to the chloride threshold value of corrosion [30], on the fresh surface. The coefficient of non-steady state migration chloride diffusion $\left(D_{n s s}\right)$ is given by Eq. (2).

$$
D_{n s s}=\frac{1}{a \cdot t}\left[x_{d}-2 \sqrt{\frac{x_{d}}{a}} \varepsilon\right]
$$

where $t$ is the duration in second and

$$
\begin{aligned}
& a=\frac{|Z| \cdot F \cdot E \cdot t}{R \cdot T \cdot d} \\
& \varepsilon=e r f^{-1}\left(1-\frac{2 C_{d}}{C_{0}}\right)
\end{aligned}
$$

where $R$ is the gas constant $(8.314 \mathrm{~J} / \mathrm{mol} \cdot \mathrm{K}), T$ is the absolute temperature, $E$ is the potential difference between anode and cathode, $d$ is the thickness of the specimen, $Z$ is the valence of ion, $F$ is Faraday constant 
$\left(96485 \mathrm{C} \cdot \mathrm{mol}^{1}\right), \operatorname{erf} f^{-1}()$ is the inverse error function, $C_{0}(0.512 \mathrm{~N})$ and $C_{d}$ $(0.03 \mathrm{~N})$ is the molar concentration of chloride ion at the upstream surface and the colour-change boundary, respectively.

$100 \mathrm{~mm}$ cubic specimens were prepared for accelerated carbonation test. The specimens were cured at room temperature in laboratory for 28 days. Then, they were dried in an oven at $60^{\circ} \mathrm{C}$ for 3 days. After they were air-cooled in laboratory to room temperature, they were sealed by paraffin. The specimens were put in a carbonation chamber (CABR-HTX12) with $5 \pm 0.2 \% \mathrm{CO}_{2}$ at $20 \pm 1.5^{\circ} \mathrm{C}$ and $70 \pm 5 \%$ relative humidity for 927 hours. After 927 hours, the specimens were cut by wedged compression. The carbonation depth was determined by colorimetric method by using solution of phenolphthalein indicator prepared according to [10].

\section{Results and discussions}

\subsection{GB survivability test}

One important indicator of the survival rate of S15 is the wet density. If significant portion of S15 was broken during the mixing process, the wet density measured was much higher than the targeted density estimated from the specific gravity of the raw materials and mix proportion. The flow diameter and percentage error of the measured from the targeted wet density is shown in Figure 4. Although the flow diameters of groups A, B, C and D1-D4 were in similar range about $300 \mathrm{~mm}$, the breakage of S15 in group $\mathrm{A}$ is much higher than groups $\mathrm{C}$ and D1-D4. The fluidity of group A was mainly by high dosage of SP with low water content. On the contrary, the water content was higher in group D with lower dosage of SP. The reason 
was that the fluidity contributed by SP mainly by the shear stress induced during mixing and it might break S15 before the SP became effective. When the fluidity was from higher water content, the effect was much faster than SP and it avoided excessive shear stress, which might break the S15, at the initial stage of wet mix. By comparing D2 and D5, when the dosage of SP is reduced by half, the fluidity of the mix dropped significantly. When the dosage of SP was less than 0.4\% (D3-D11, E1 and F1), the breakage of S15 was significant (more than 10\%) even through the ultimate fluidity was similar. When the dosage of SP was less than $0.2 \%$, for some cases, the effect of SP could be activated only after much longer duration of mixing (D8-D11). For the given water content and SP dosage, the breakage of S15 increased with increased dosage of HPMC. The addition of HPMC increased the viscosity of fresh mix. By comparing D5-D7, with $316 \mathrm{~kg} / \mathrm{m}^{3}$ water content and $0.2 \% \mathrm{SP}$ dosage, the flow diameter increased from $220 \mathrm{~mm}$ to $350 \mathrm{~mm}$ when the dosage of HPMC decreased from $0.15 \%$ to $0 \%$. When the dosage of SP increased with the given water content, higher HPMC dosage could be used to achieve similar flow diameter (D1-D4 and D6). In summary, the general guidelines for the mix design of using S15, which is much more fragile compared to the lightweight aggregates used in other literature, are that (i) the water content is about $300 \mathrm{~kg} / \mathrm{m}^{3}$, (ii) SP content is at least $0.4 \%$ and (iii) the HPMC content is about $0.1 \%$, to achieve desirable survival rate of $\mathrm{S} 15$ after mixing.

\subsection{Tensile test of $\mathrm{LSHCC}$}

The stress-strain curves of the tensile test of GI (OPC-sand blend), GII (OPC-FA-sand blend) and GIII (OPC-FA-GGBS-sand blend) are shown in 
Figures 5, 6 and 7, respectively. The first crack strength, ultimate tensile strength and tensile ductility is shown in Figure 8. The tensile ductility is defined as the tensile strain corresponding to the ultimate tensile strength. The error bars in Figure 8 represent the $90 \%$ confidence interval of the first crack and ultimate tensile strength based on the three experimental results by $\mu \pm t_{0.05,2} \cdot \sigma / \sqrt{2}=\mu \pm 2.920 \sigma / \sqrt{2}$, where $t_{0.05,2}$ is the upper 5 percentile of the t-distribution with 2 degrees of freedom, $\mu$ and $\sigma$ are the mean and standard deviation of the three samples, respectively. The three strokes (top, bottom and middle) of the uniform bars in Figure 8 show the tensile ductility of the three tensile tests. The ductility is classified as low, medium and high corresponding to GI-2:3 (0.69\%), GI-4:1 (2.15\%) and GI-2:1 (4.70\%), which will be used to demonstrate the effectiveness of using LSHCC with different tensile ductility to retrofit unreinforced masonry wall in section 5 .

In GI, GI-1, GI-2 and GI-4, with $2 \%$ volume fraction of fibre, exhibited low to high tensile ductility. The aggregates (sand + GB) to binder ratios of GI-1, GI-2 and GI-4 were 0.057, 0.225 and 0.58, respectively. The first crack strength of GI-1 (2.64 MPa) and GI-4 (2.63 MPa) was similar while that of GI-2 (1.99 MPa) was significantly lower. It might be because the air content of GI-2 was higher by the high negative percentage error of the measured wet density relative to the estimated one. The ultimate tensile strength of GI-1 was higher than GI-2 and GI-4. It might be because of the better bond strength at the fibre-matrix interface of higher binder content of GI-1. GI-3 and GI-5 with fibre volume fraction of $1.75 \%$ did not exhibit strain hardening behaviour but as conventional fibre reinforced concrete. The flow diameters of GI-3 and GI-5 were in the range of $120-130 \mathrm{~mm}$ which were smaller than 
GI-1, GI-2 and GI-4 (between $135 \mathrm{~mm}$ and $170 \mathrm{~mm}$ ). The percentage error of the measured wet density relative to the estimated one of GI-3 and GI-5 was significantly higher than GI-1, GI-2 and GI-4. It indicated that GB was damaged during mixing and it is detrimental to the multiple-crack formation. The fibre volume fraction of GII was $1.75 \%$ except GII-7 (1.50\%). The flow diameters were generally higher $(180 \mathrm{~mm}-200 \mathrm{~mm})$ than GI because of the spherical morphology of FA particle except GII-1 (160 mm) and GII-5 $(140 \mathrm{~mm})$, of which the FA to OPC ratio was lower and the tensile ductility was significantly lower than the other five. With the higher flow diameter, the variation of stress-strain relationship of the same mix proportion was less. For GII-1 and GII-5, the flow diameter was the smallest and the consistency of the stress-strain relationship was the lowest. The first crack strength of GII-2 and GII-3 was lower than the other five because the air content was higher deduced from the negative percentage error of the measured wet density relative to the estimated one. The main difference between GII$6(1.75 \%$ vol $)$ and GII-7 (1.50\%) was the fibre volume fraction with similar flow diameter. Although the first crack strength and ultimate tensile strength of GII-7 was about $12 \%$ and $14 \%$ lower than GII-6, respectively, the tensile ductility of them were similar (3.5\% for GII-6 and $3.31 \%$ for GII-7). That means the tensile ductility of LSHCC with dry density about $1,250 \mathrm{~kg} / \mathrm{m}^{3}$ can be maintained at medium to high range.

In GIII, the tensile ductility was in the range of low to high ductility except GIII-4, which did not exhibit strain hardening behaviour. GIII-4 did not contain any FA. The flow diameter was only $130 \mathrm{~mm}$ and the percentage error of the measured wet density was significantly higher than GIII-1, GIII-2 and 
GIII-3. The flow diameter of GIII-1 was the highest and the tensile ductility was the highest. Although the fibre volume fraction of GIII-3 was $2.00 \%$ compared to $1.75 \%$ of GIII-2, the tensile ductility was similar. Although the GGBS content of GIII-2 was higher than GIII-3, the first crack strength and ultimate tensile strength of GIII-2 was higher than GIII-3. Similar to the observation of GI and GII, the first crack strengths of GIII-1 (2.37 MPa) and GIII-3 (2.48 MPa) were lower than GIII-2 (2.71 MPa) and GIII-4 (3.19 MPa) because of the higher air content indicated by the negative percentage error of the measured wet density relative to estimated one.

\subsection{Compressive strength, thermal conductivity and durability parameters}

The compressive strength, thermal conductivity, water permeability, chloride diffusivity and carbonation rate were measured for the selected set of samples. For comparison and cross-reference to other literature, those engineering properties of reference concrete samples with unknown mix formulation for precast reinforced concrete building fasçade (C35/45), provided by a local concrete producer in Hong Kong, were also measured and named Ref in Figure 9.

Figure 9a shows the density, compressive strength and coefficient of thermal conductivity of the selected groups of samples. The compressive strength of the reference concrete sample (C35/45) was $54 \mathrm{MPa}$. Since the aggregates (sand + GB) to binder ratio of GI-4 was 0.58 compared to GI-2 of 0.225 , the compressive strength of GI-4 (13.6 MPa) was $41 \%$ lower than GI2 (23.2 MPa). The compressive strength of GII-3, GII-4, which consisted of high fraction of FA (OPC-to-FA ratio $=1: 4$ ), was lower compared with other samples as expected because of the low reactivity of FA. However, with 
OPC-to-FA ratio 2:1 and higher density, the compressive strength of GII-5 was 31.1 MPa. The compressive strength of GIII-2 (25.9 MPa) and GIII-3 (24.7 MPa) was comparable with GI-2. Since GIII-1 consisted of $60 \%$ of FA in the binder and the density is lower, the compressive strength of GIII-1 (19.8 MPa) was about 22\% lower than GIII-2 and GIII-3. The compressive strength of LSHCC with the dry density of about $1,200-1,300 \mathrm{~kg} / \mathrm{m}^{3}$ in this study was lower than the values reported in [32] that the compressive strength was 41.2 MPa and 21.8 MPa for density of $1,460 \mathrm{~kg} / \mathrm{m}^{3}$ and $930 \mathrm{~kg} / \mathrm{m}^{3}$, respectively. However, the GB used in [32] was S60 and S38 for the low and ultra-low density LSHCC while S15, the thermal conductivity of which was about half and $27 \%$ of S60 and S38, respectively, was used in this study. It is more effective to use S15 for thermal insulation application. 20\% mass of S60 and 50\% mass of S38 to cement was used in [32] while there was about $5-6 \%$ to total binder employed in this study. Hence, the material cost of the LSHCC in this study is significantly lower. Since the crush strength of S15 is about $7.6 \%$ and $3.0 \%$ of S60 and S38, respectively, the compressive strength is expected to be lower than LSHCC with S60 or S38.

The coefficient of thermal conductivity $(\lambda)$ of the reference concrete was $2.08 \mathrm{~W} / \mathrm{m} \cdot \mathrm{K}$ which was at least about four times higher than the selected set of LSHCC in this study. In GI, the dry density of GI-2 and GI-4 was the same, but the $\lambda$-value of GI-4 $(0.42 \mathrm{~W} / \mathrm{m} \cdot \mathrm{K})$ was about $21 \%$ lower than GI-2 $(0.53 \mathrm{~W} / \mathrm{m} \cdot \mathrm{K})$ while the sand content of GI-4 was about three times of GI-2. It can be explained by the high porosity indicated by low compressive strength [55] of GI-4 (13.6 MPa) compared with GI-2 (23.2 MPa). In GII, the compressive strength of GII-3 and GII-4 was similar, but the density 
of GII-3 $\left(1,119 \mathrm{~kg} / \mathrm{m}^{3}\right)$ is lower than GII-4 $\left(1,277 \mathrm{~kg} / \mathrm{m}^{3}\right)$. It indicated high porosity of the matrix of GII-4, so the $\lambda$-value of GII- 4 was lower than GII3. For GII-5, the density and compressive strength was higher than GI-2 but the $\lambda$-value of GII- 5 was smaller. The $\lambda$-value decreased with increased replacement of OPC by FA up to $30 \%$ of replacement [14, 15, 52]. For GIII, the $\lambda$-value decreased with density. By comparing GIII-3 and GI-2, both the compressive strength and density of GIII-3 was higher than GI-2 but the $\lambda$-value of GIII-3 was lower than GI-2. It was because of the replacement OPC by GGBS $[14,52]$.

Figure $9 \mathrm{~b}$ shows the results of the test of water permeability. The plot is in semi-log of the y-axis. The height of the bars represented the mean value and only the upper bound of the error bar for the $90 \%$ confidence interval is shown. The coefficient of water permeability of ECC-M45 report in [31] is shown in the dash line in Figure 9b. All of them were comparable with the reference normal concrete and ECC-M45 except GII-3 and GII-4. GII-3 and GII-4 contained high proportion of FA (FA-to-OPC ratio $=4: 1)$ and the compressive strength was low, which indicated high porosity of the matrix.

The results of the coefficient of chloride diffusivity $\left(D_{n s s}\right)$ are shown in Figure 9c. The value of $D_{n s s}$ of the reference concrete was $1.59 \times 10^{-11} \mathrm{~m}^{2} / \mathrm{s}$. In GI, $D_{n s s}$ of GI-2 was lower than the reference concrete as expected because there was no transition zone in GI-2. While the coefficient of water permeability of GI-4 was similar to GI-2, $D_{n s s}$ of GI-4 was much higher than GI-2 because the cement content of GI-2 was much higher than GI-4 and there might be chloride binding by $\mathrm{C}_{3} \mathrm{~A}$ in OPC [58]. In GII, although the water permeability of GII-3 and GII-4 was higher than the reference concrete, 
$D_{n s s}$ was lower than the reference concrete because of chloride binding of FA [58]. When the water permeability of GII-5 was similar with the reference concrete, $D_{n s s}$ was only $2.6 \%$ of the reference concrete. In GIII, the water permeability of GIII-1 and GIII-2 was similar to the reference concrete, $D_{n s s}$ was much lower because of chloride binding of GGBS [39]. When the water permeability of GIII-3 was lower, $D_{n s s}$ was further reduced.

Carbonation depends on the porosity, internal moisture content and the availability of Portlandite. Figure 9d shows the results of carbonation rate. The carbonation rate of the reference concrete was $3.8 \mathrm{~mm} / \mathrm{month}^{1 / 2}$. In general, the replacement of OPC by FA and GGBS increases the carbonation rate for the same strength grade because the pozzolanic reaction of FA and GGBS consumes Portlandite although the pore structure is refined [4, 18, 25]. However, the compressive strength of different mixes was different so the carbonation rate was not comparable directly. When the carbonation rate and compressive strength of the mixes with FA and GGBS (GII and GIII) was plotted (Figure 10, the relationship follows a linear line $\left(\mathrm{R}^{2}=0.91\right)$. However, if the linear relationship is used for GI, it overestimates the carbonation rate from compressive strength. It is because there is no pozzolanic reaction in GI so more Portlandite for carbonation reaction.

\section{Pushover analysis of unreinforced masonry wall strengthened by LSHCC}

Pushover analysis was conducted for masonry walls with and without LSHCC in order to investigate the effects of the LSHCC on the in-plane and out-of-plane lateral force resisting capacities of a unreinforced masonry 
wall. Three sets of LSHCC with different ductility but similar strength were selected from the experimental results of the tensile test in section 4.2 for the analysis corresponding to high (GI-2:1), medium (GI-4:1) and low (GI-2:3) tensile ductility. The meaning of GI-2:1 was the stress-strain relationship of the first curve in GI-2 (OPC-sand blend). The dimensions of a typical low height-to-length ratio masonry wall in the analysis were $6 \mathrm{~m} \times 3 \mathrm{~m} \times 0.23 \mathrm{~m}$. The thickness of LSHCC was $10 \mathrm{~mm}$ thick applied on both sides of the wall.

\subsection{Finite Element Model and Validation}

Pushover analysis was conducted through a three-dimensional model in general finite element software ANSYS (Figure 11). The wall was fixed at the base and subjected to uniformly distributed load at the top. At each step, incremental displacement was applied at the top of wall along and perpendicular to the wall surface for in-plane and out-of-plane pushover analysis, respectively.

The masonry wall was modelled as 3D solid elements with unreinforced smeared crack material models combined with multilinear isotropic plasticity as proposed by [2]. The mechanical properties of the masonry were referred to the test results in [20] and they are shown in Table 1. The parameters of the unreinforced masonry wall model were calibrated from the in-plane pushover experiment in [21] and the calibrated results are shown in Figure 12a.

The LSHCC was modelled as 3D solid elements with reinforced smeared crack material models $[50,2]$. The first crack strength, ultimate tensile strength and tensile ductility of the selected experimental data was retrieved from section 4.2. Other properties such as tensile stress-strain inputs and volumetric ratio of the reinforcement were calibrated to the stress-strain re- 
lationship in section 4.2. The calibrated/simplified constitutive relations of LSHCC are shown in Figure 12b.

\subsection{Analytical Results}

Figure 13 shows the pushover response (base shear versus drift at the top of the wall) for (a) in-plane loading and (b) out-of-plane loading. Several critical states are indicated as markers in Figure 13 including the first crack in masonry, crushing in masonry, crushing in LSHCC and tensile fracture in LSHCC elements. For in-plane loading case, the LSHCC significantly increased the strength of the wall from $43 \%$ to $76 \%$ depending on the ductility of the LSHCC as seen in Figure 13a. The LSHCC did not change the drift capacity where the wall started crack due to the strain compatibility but it influenced the post-cracking behaviour of the wall. The low ductility LSHCC had a lower overall ductility compared to the wall without LSHCC because the failure of the wall with low ductility LSHCC was controlled by the rupture of the fibre. The medium and high ductility LSHCC increased overall ductility of the wall. The failures of the wall with medium and high ductility LSHCC were initiated from the crushing of the masonry and LSHCC elements respectively. The masonry element started to crush earlier in the wall with medium ductility LSHCC than high ductility LSHCC and it might be because the medium ductility LSHCC was slightly stronger than the high ductility LSHCC (refer to Figure 12b). The stronger LSHCC could provide larger confinement to the masonry and increase the force transferred through the wall, which in turn made the masonry element to crush earlier.

For the out-of-plane loading case, the LSHCC also showed significant increase in the strength of the wall as seen in Figure 13b. The medium and 
high ductility LSHCC significantly increased the overall ductility of the wall. The overall ductility of the wall increased as the increase of the ductility in the LSHCC material because the failure of the wall was controlled by the tensile fracture of LSHCC. Compared to the in-plane loading case, the LSHCC was more effective to increase the overall ductility for the out-of-plane loading. The higher ductility achieved in the out-of-plane loading was possibly because the response of the wall was controlled by flexural deformation in the outof-plane loading while it was controlled by shear deformation in the in-plane loading. Figure 14 shows the crack pattern in the masonry wall element at $0.3 \%$ drift for the wall without LSHCC and with the medium ductility LSHCC under the in-plane loading. The wall with LSHCC had more cracks than the wall without LSHCC because the confinement of the LSHCC allowed the masonry wall to transfer more forces and resulted in more cracks in the masonry wall.

Figure 15a shows the relationship between plastic strain in the LSHCC and the drift at top of the wall. The plastic strain is normalized by the ultimate strain which is defined as the strain at peak strength of LSHCC (refer to Figure 12b). The fibre in the low ductility LSHCC reached its ultimate strain in both in-plane (at $0.26 \%$ drift) and out-of-plane (at $1.2 \%$ drift) loadings which indicated its insufficient ductility for strengthening the masonry wall. The fibre in the medium ductility LSHCC just reached the ultimate strain at a fairly large drift (3.7\%) for the out-of-plane loading while it did not reach the ultimate strain under the in-plane loading. The fibre in the high ductility LSHCC did not reach the ultimate strain under both inplane and out-of-plane loadings. 
The rigid and continuous model assumption between the masonry wall and LSHCC was examined by the bond stress at the LSHCC/masonry interface. Figure $15 \mathrm{~b}$ shows the bond stress between the wall and LSHCC interface. As seen, the bond stress was higher in the out-of-plane loading case than that in the in-plane loading case due to higher drift occurred in the out-of-plane loading. The maximum bond stress was much lower than the bond strength $(0.24 \mathrm{MPa})$ estimated from the tests in fibre reinforced cementitious matrix (FRCM) composite reported in literature [46].

\section{Conclusions}

LSHCC based on S15 GB with dry density about $1,350 \mathrm{~kg} / \mathrm{m}^{3}$ has been developed that can achieve 2-4\% tensile strain. The proposed survivability test of mortar can provide a guideline of water content as well as the dosage of superplasticiser and viscosity modifying agent. The increase of water content is more beneficial for the survivability of hollow glass bubble than SP because the initial excessive shear stress during mixing may damage the GB. The tensile ductility of OPC-FA-sand blend and OPC-FA-GGBS blend was generally better than the OPC-sand blend while the OPC-FA-blend was the best in this study. The compressive strength depended on the density as well as the porosity in the matrix. The thermal conductivity of LSHCC is about $25 \%$ of normal structural concrete. The coefficient of water permeability of LSHCC is comparable to normal concrete. The coefficient of chloride diffusivity is commonly lower than normal concrete because of the chloride binding of FA and GGBS. However, the carbonation rate of LSHCC is commonly higher than normal concrete. 
The experimental stress-strain relationship of LSHCC under tensile was used for pushover analysis of a unreinforced masonry wall. From the pushover analysis results, the LSHCC can increase the strength and ductility of the masonry under both in-plane and out-of-plane loadings by providing the confinement and allowing more forces transferring through the masonry element. To ensure an efficient retrofit for the masonry, the LSHCC needs to have a sufficient ductility. The LSHCC is more effective on increasing the overall ductility of the wall for the out-of-plane loading due to the flexural controlled deformation in this direction.

\section{Acknowledgement}

The work of this paper is sponsored by ITP/005/11NP from the Innovation and Technology Fund of Innovation and Technology Commission of the government of Hong Kong SAR and and Global Challenges Research Fund of Engineering and Physical Sciences Research Council, UK (EP/P510749/1/R33466/R33471).

\section{References}

[1] Al-Dahawi, A., Yldrm, G., Öztürk, O., Şahmaran, M., 2017. Assessment of self-sensing capability of Engineered Cementitious Composites within the elastic and plastic ranges of cyclic flexural loading. Construction and Building Materials 145, 1-10.

[2] Aldemir, A., Erberik, M. A., Demirel, I. O., Sucuoğlu, H., 2013. Seismic performance assessment of unreinforced masonry buildings with a hybrid modeling approach. Earthquake Spectra 29 (1), 33-57. 
[3] Ali, M. A. E. M., Nehdi, M. L., 2017. Innovative crack-healing hybrid fiber reinforced engineered cementitious composite. Construction and Building Materials 150, 689-702.

[4] Ashraf, W., 2016. Carbonation of cement-based materials: Challenges and opportunities. Construction and Building Materials 120, 558-570.

[5] Baroghel-Bouny, V., Belin, P., Maultzsch, M., Henry, D., 2007. AgNO3 spray tests: Advantages, weaknesses, and various applications to quantify chloride ingress into concrete. Part 1: Non-steady-state diffusion tests and exposure to natural conditions. Materials and Structures/Materiaux et Constructions 40 (8), 759-781.

[6] Baroghel-Bouny, V., Belin, P., Maultzsch, M., Henry, D., 2007. AgNO3 spray tests: Advantages, weaknesses, and various applications to quantify chloride ingress into concrete. Part 2: Non-steady-state migration tests and chloride diffusion coefficients. Materials and Structures/Materiaux et Constructions 40 (8), 783-799.

[7] Berardinis, P. D., Rotilio, M., Marchionni, C., Friedman, A., 2014. Improving the energy-efficiency of historic masonry buildings. A case study: A minor centre in the Abruzzo region, Italy. Energy and Buildings 80, 415-423.

[8] British Standards Institution, 1978. BS 4550-5:1978 Methods of testing cement. Standard sand for concrete cubes. BSI.

[9] British Standards Institution, 1999. BS EN 1015-3:1999 Methods of test 
for mortar for masonry. Determination of consistence of fresh mortar (by flow table). BSI.

[10] British Standards Institution, 2006. BS EN 14630:2006 Products and systems for the protection and repair of concrete structures. Test methods. Determination of carbonation depth in hardened concrete by the phenolphthalein method. BSI.

[11] Capozucca, R., 2017. Experimental response of historic brick masonry under biaxial loading. Construction and Building Materials 154, 539556.

[12] Constantinescu, S., 2017. Study of Confined Masonry Buildings in Seismic Areas. In: Energy Procedia. Vol. 112. pp. 545-554.

[13] Şahmaran, M., Al-Emam, M., ldı rım, G. Y., Şimşek, Y. E., Erdem, T. K., Lachemi, M., 2015. High-early-strength ductile cementitious composites with characteristics of low early-age shrinkage for repair of infrastructures. Materials and Structures/Materiaux et Constructions 48 (5), 1389-1403.

[14] Demirboğa, R., 2003. Influence of mineral admixtures on thermal conductivity and compressive strength of mortar. Energy and Buildings 35 (2), 189-192.

[15] Demirboğa, R., Gül, R., 2003. The effects of expanded perlite aggregate, silica fume and fly ash on the thermal conductivity of lightweight concrete. Cement and Concrete Research 33 (5), 723-727. 
[16] Dizhur, D., Griffith, M., Ingham, J., 2014. Out-of-plane strengthening of unreinforced masonry walls using near surface mounted fibre reinforced polymer strips. Engineering Structures 59, 330-343.

[17] Drysdale, R. G., Essawy, A. S., 1988. Out-of-plane bending of concrete block walls. Journal of Structural Engineering (United States) 114 (1), $121-133$.

[18] Ekolu, S. O., 2016. A review on effects of curing, sheltering, and CO2 concentration upon natural carbonation of concrete. Construction and Building Materials 127, 306-320.

[19] Galati, N., Tumialan, G., Nanni, A., 2006. Strengthening with FRP bars of URM walls subject to out-of-plane loads. Construction and Building Materials 20 (1-2), 101-110, cited By :35.

[20] Ganz, H., Thürlimann, B., 1982. Tests on the biaxial strength of masonry. Tech. Rep. Report No. 7502-3, Institute of Structural Engineering, ETH Zurich, Zurich, Switzerland.

[21] Ganz, H., Thürlimann, B., 1984. Tests on masonry walls under normal and shear loading. Tech. Rep. Report No. 7502-4, Institute of Structural Engineering, ETH Zurich, Zurich, Switzerland.

[22] Gilstrap, J., Dolan, C., 1998. Out-of-plane bending of FRP-reinforced masonry walls. Composites Science and Technology 58 (8), 1277-1284.

[23] Graziotti, F., Tomassetti, U., Kallioras, S., Penna, A., Magenes, G., 2017. Shaking table test on a full scale URM cavity wall building. Bulletin of Earthquake Engineering, 1-36. 
[24] Griffith, M., Magenes, G., Melis, G., Picchi, L., 2003. Evaluation of outof-plane stability of unreinforced masonry walls subjected to seismic excitation. Journal of Earthquake Engineering 7 (SPEC. 1), 141-169.

[25] Han-Seung, L., Wang, X., 2016. Evaluation of compressive strength development and carbonation depth of high volume slag-blended concrete. Construction and Building Materials 124, 45-54.

[26] Huang, X., Ranade, R., Zhang, Q., Ni, W., Li, V. C., 2013. Mechanical and thermal properties of green lightweight engineered cementitious composites. Construction and Building Materials 48, 954-960.

[27] Karantoni, F., Pantazopoulou, S., Ganas, A., 2017. Confined masonry as practical seismic construction alternative-the experience from the 2014 Cephalonia earthquake. Frontiers of Structural and Civil Engineering, $1-21$.

[28] Keskin, S. B., Sulaiman, K., Sahmaran, M., Yaman, I. O., 2013. Effect of presoaked expanded perlite aggregate on the dimensional stability and mechanical properties of engineered cementitious composites. Journal of Materials in Civil Engineering 25 (6), 763-771.

[29] Khalfan, M., El-Dakhakhni, W. W., Tait, M. J., 2016. Seismic Risk Assessment of Nonengineered Residential Buildings in Developing Countries. Journal of Performance of Constructed Facilities 30 (5).

[30] Kim, M., Yang, E., Yi, S., 2013. Application of the colorimetric method to chloride diffusion evaluation in concrete structures. Construction and Building Materials 41, 239-245. 
[31] Lepech, M. D., Li, V. C., 2009. Water permeability of engineered cementitious composites. Cement and Concrete Composites 31 (10), 744-753.

[32] Li, V. C., 2012. Tailoring ECC for Special Attributes: A Review. International Journal of Concrete Structures and Materials 6 (3), 135-144.

[33] Li, V. C., Mishra, D. K., -. Wu, H., 1995. Matrix design for pseudostrain-hardening fibre reinforced cementitious composites. Materials and Structures 28 (10), 586-595.

[34] Lignola, G. P., Sarno, L. D., Ludovico, M. D., Prota, A., 2016. The protection of artistic assets through the base isolation of historical buildings: a novel uplifting technology. Materials and Structures/Materiaux et Constructions 49 (10), 4247-4263.

[35] Lin, Y., Lawley, D., Wotherspoon, L., Ingham, J., 2016. Out-ofplane Testing of Unreinforced Masonry Walls Strengthened Using ECC Shotcrete. Structures 7, 33-42.

[36] Lin, Y., Wotherspoon, L., Scott, A., Ingham, J., 2014. In-plane strengthening of clay brick unreinforced masonry wallettes using ECC shotcrete. Engineering Structures 66, 57-65.

[37] Liu, H., Zhang, Q., Gu, C., Su, H., Li, V., 2017. Self-healing of microcracks in Engineered Cementitious Composites under sulfate and chloride environment. Construction and Building Materials 153, 948-956.

[38] Lu, C., Leung, C. K. Y., 2016. A new model for the cracking process and tensile ductility of Strain Hardening Cementitious Composites (SHCC). Cement and Concrete Research 79, 353-365. 
[39] Luo, R., Cai, Y., Wang, C., Huang, X., 2003. Study of chloride binding and diffusion in GGBS concrete. Cement and Concrete Research 33 (1), $1-7$.

[40] Maalej, M., Lin, V. W. J., Nguyen, M. P., Quek, S. T., 2010. Engineered cementitious composites for effective strengthening of unreinforced masonry walls. Engineering Structures 32 (8), 2432-2439.

[41] Maoduš, N., Agarski, B., Mišulić, T. K., Budak, I., Radeka, M., 2016. Life cycle and energy performance assessment of three wall types in south-eastern Europe region. Energy and Buildings 133, 605-614.

[42] Marshall, D. B., Cox, B. N., 1988. A J-integral method for calculating steady-state matrix cracking stresses in composites. Mechanics of Materials 7 (2), 127-133.

[43] Nematollahi, B., Ranade, R., Sanjayan, J., Ramakrishnan, S., 2017. Thermal and mechanical properties of sustainable lightweight strain hardening geopolymer composites. Archives of Civil and Mechanical Engineering 17 (1), 55-64.

[44] Nematollahi, B., Sanjayan, J., Shaikh, F. U. A., 2016. Matrix design of strain hardening fiber reinforced engineered geopolymer composite. Composites Part B: Engineering 89, 253-265.

[45] Ohno, M., Li, V. C., 2014. A feasibility study of strain hardening fiber reinforced fly ash-based geopolymer composites. Construction and Building Materials 57, 163-168. 
[46] Olivito, R. S., Codispoti, R., Cevallos, O. A., 2016. Bond behavior of Flax-FRCM and PBO-FRCM composites applied on clay bricks: Experimental and theoretical study. Composite Structures 146, 221-231.

[47] Papanicolaou, C., Triantafillou, T., Papathanasiou, M., Karlos, K., 2008. Textile reinforced mortar (TRM) versus FRP as strengthening material of URM walls: Out-of-plane cyclic loading. Materials and Structures/Materiaux et Constructions 41 (1), 143-157.

[48] Papanicolaou, C. G., Triantafillou, T. C., Karlos, K., Papathanasiou, M., 2007. Textile-reinforced mortar (TRM) versus FRP as strengthening material of URM walls: In-plane cyclic loading. Materials and Structures/Materiaux et Constructions 40 (10), 1081-1097.

[49] Petrovčič, S., Kilar, V., 2017. Seismic Retrofitting of Historic Masonry Structures with the Use of Base Isolation-Modeling and Analysis Aspects. International Journal of Architectural Heritage 11 (2), 229-246.

[50] Pramono, E., Willam, K., 1989. Fracture energy-based plasticity formulation of plain concrete. Journal of Engineering Mechanics 115 (6), $1183-1204$.

[51] Shi, L., Lu, Y., Bai, Y., 2017. Mechanical and Electrical Characterisation of Steel Fiber and Carbon Black Engineered Cementitious Composites. In: Procedia Engineering. Vol. 188. pp. 325-332.

[52] Tang, S. W., Chen, E., Shao, H. Y., Li, Z. J., 2015. A fractal approach to determine thermal conductivity in cement pastes. Construction and Building Materials 74, 73-82. 
[53] Tu, Y., Chuang, T. L. P., Yang, Y., 2010. Out-of-plane shaking table tests on unreinforced masonry panels in RC frames. Engineering Structures 32 (12), 3925-3935.

[54] Wang, S., Li, V. C., 2003. Lightweight engineered cementitious composites (ECC). In: Naaman, A. E., Reinhardt, H. W. (Eds.), Proceedings of HPFRCC. pp. 379-390.

[55] Widodo, S., Ma'Arif, F., Gan, B. S., 2017. Thermal Conductivity and Compressive Strength of Lightweight Mortar Utilizing Pumice Breccia as Fine Aggregate. In: Procedia Engineering. Vol. 171. pp. 768-773.

[56] Xu, B., Li, Z., 2014. Performance of novel thermal energy storage engineered cementitious composites incorporating a paraffin/diatomite composite phase change material. Applied Energy 121, 114-122.

[57] Yu, J., Li, H., Leung, C. K. Y., Lin, X., Lam, J. Y. K., Sham, I. M. L., Shih, K., 2017. Matrix design for waterproof Engineered Cementitious Composites (ECCs). Construction and Building Materials 139, 438-446.

[58] Yuan, Q., Shi, C., Schutter, G. D., Audenaert, K., Deng, D., 2009. Chloride binding of cement-based materials subjected to external chloride environment - A review. Construction and Building Materials 23 (1), $1-13$.

[59] Zhang, Z., Zhang, Q., 2017. Self-healing ability of Engineered Cementitious Composites (ECC) under different exposure environments. Construction and Building Materials 156, 142-151. 


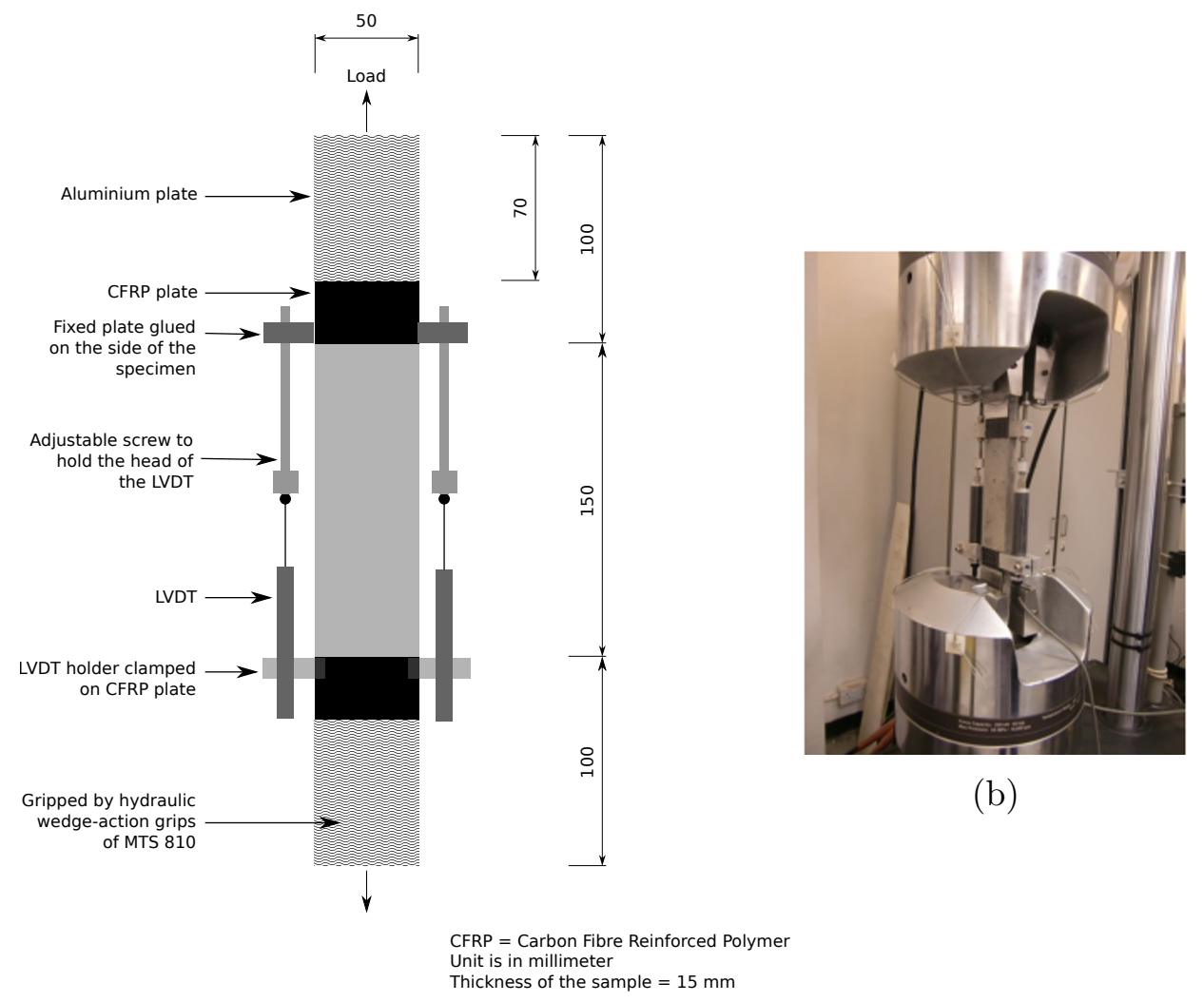

(a)

Figure 1: (a) Schematic diagram of the direct tensile test of SHCC. (b) Tensile test configuration. 


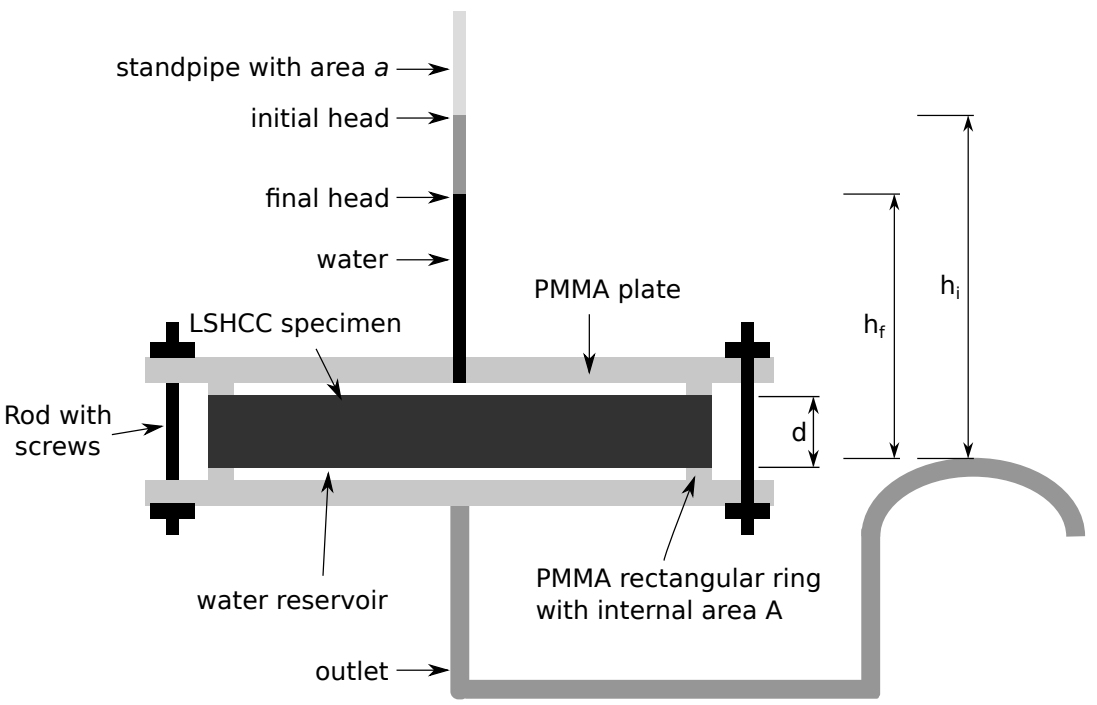

Figure 2: Schematic diagram of the falling head test. 


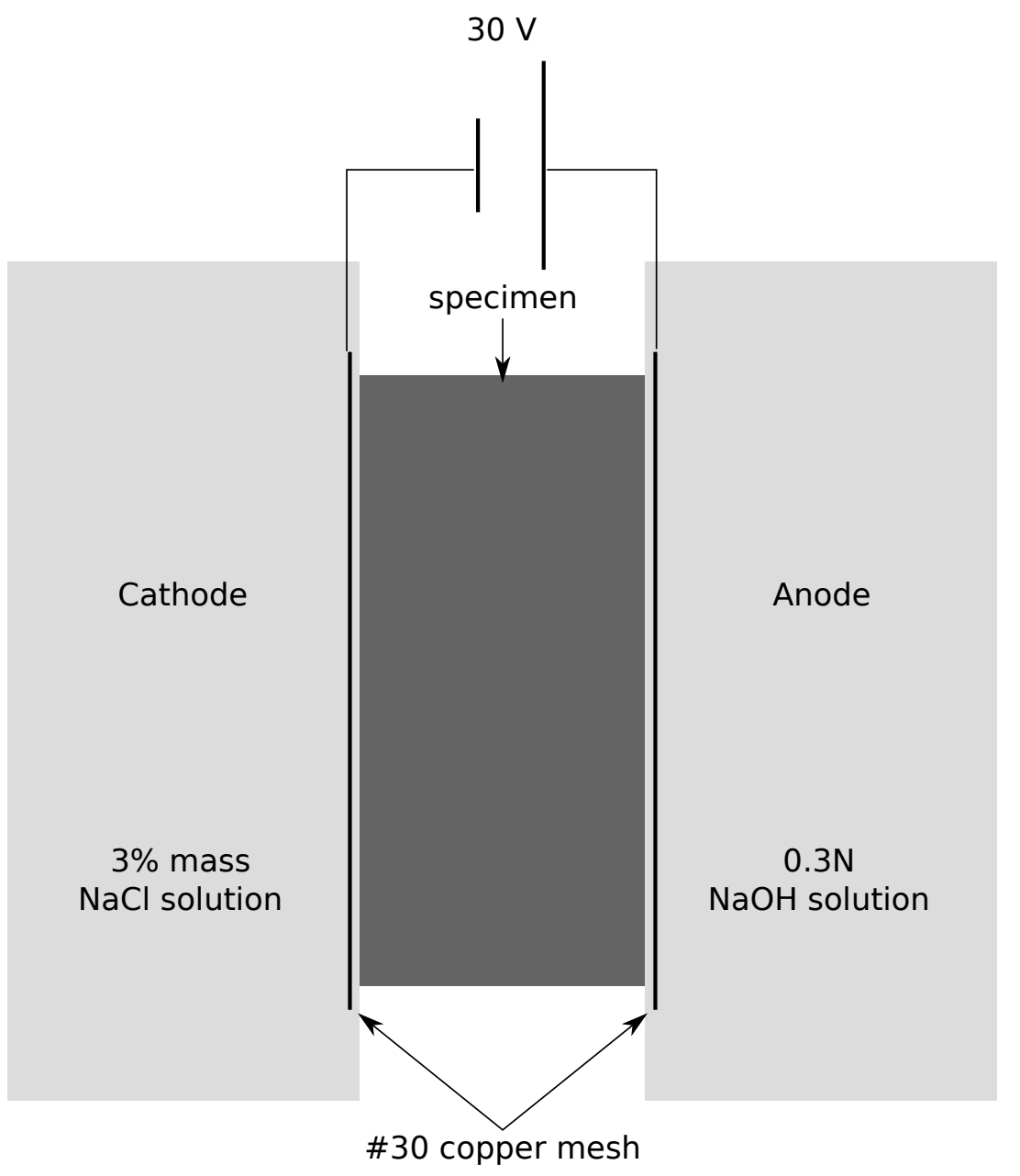

Figure 3: Schematic diagram of rapid chloride diffusion test. 


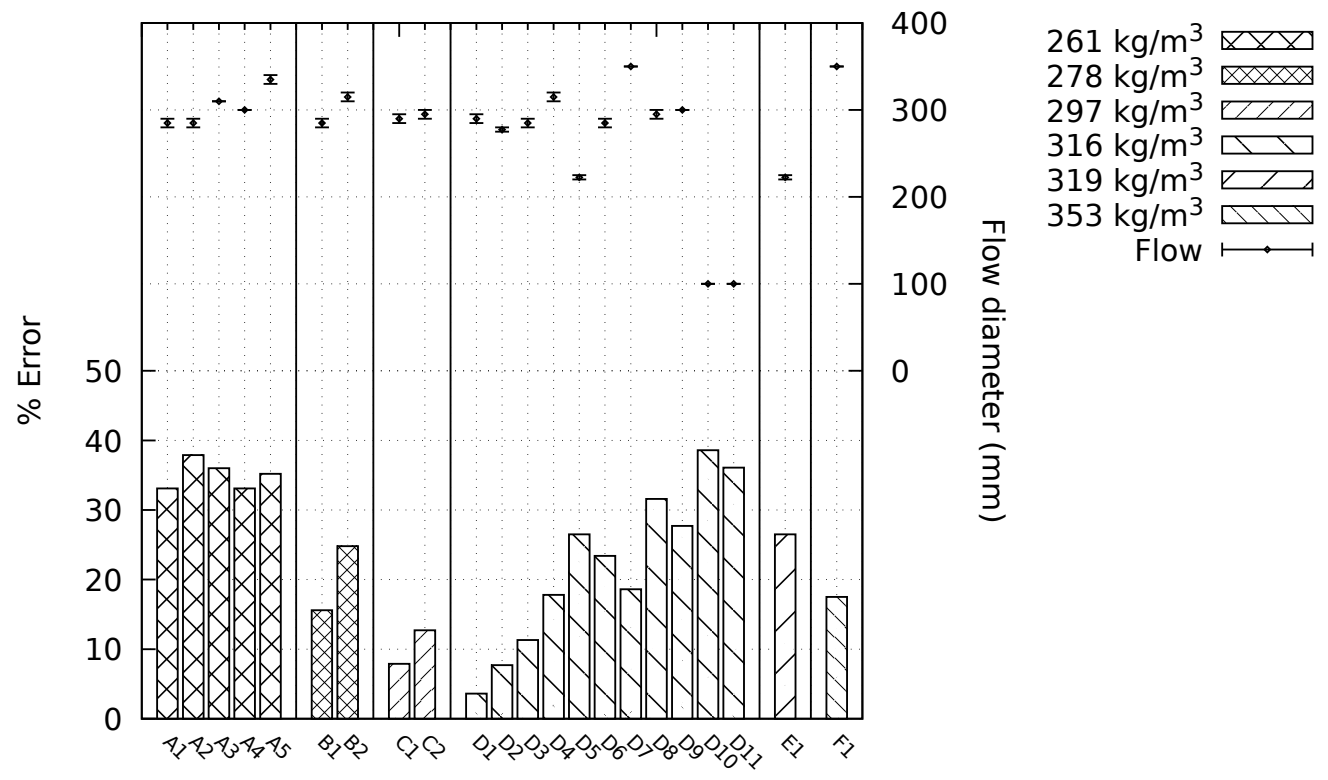

Figure 4: Deviation of wet density and flow diameter results of mortar test. 

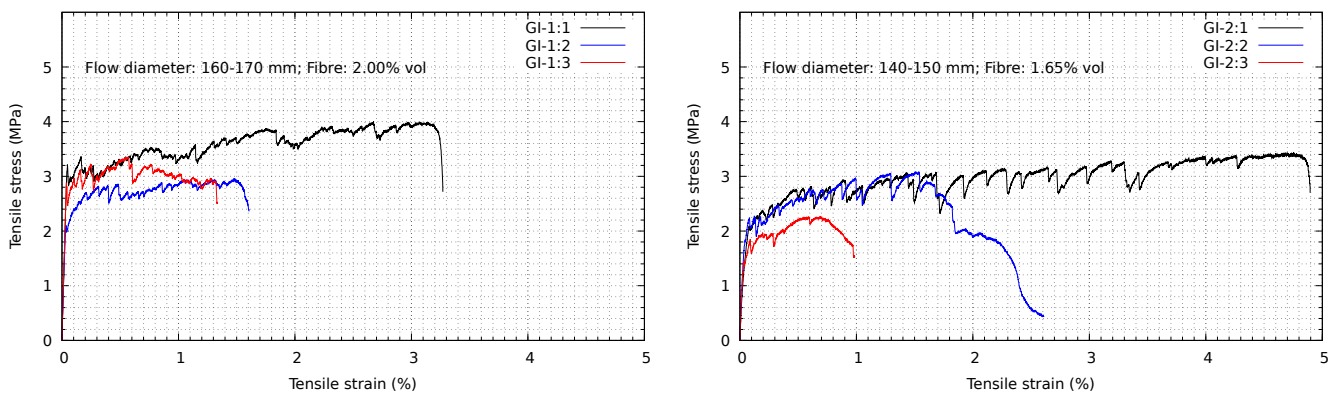

(a) GI-1

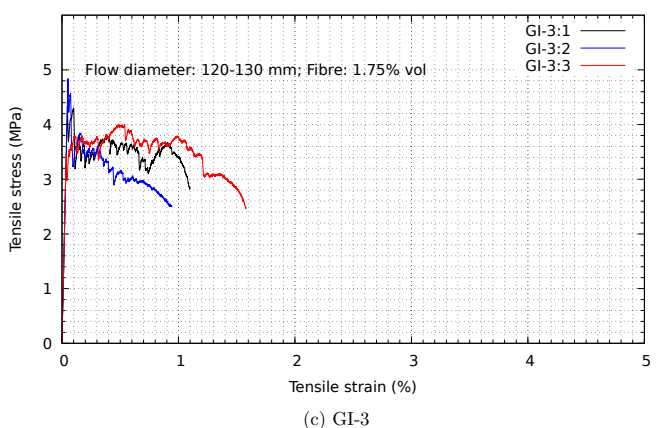

(b) GI-2
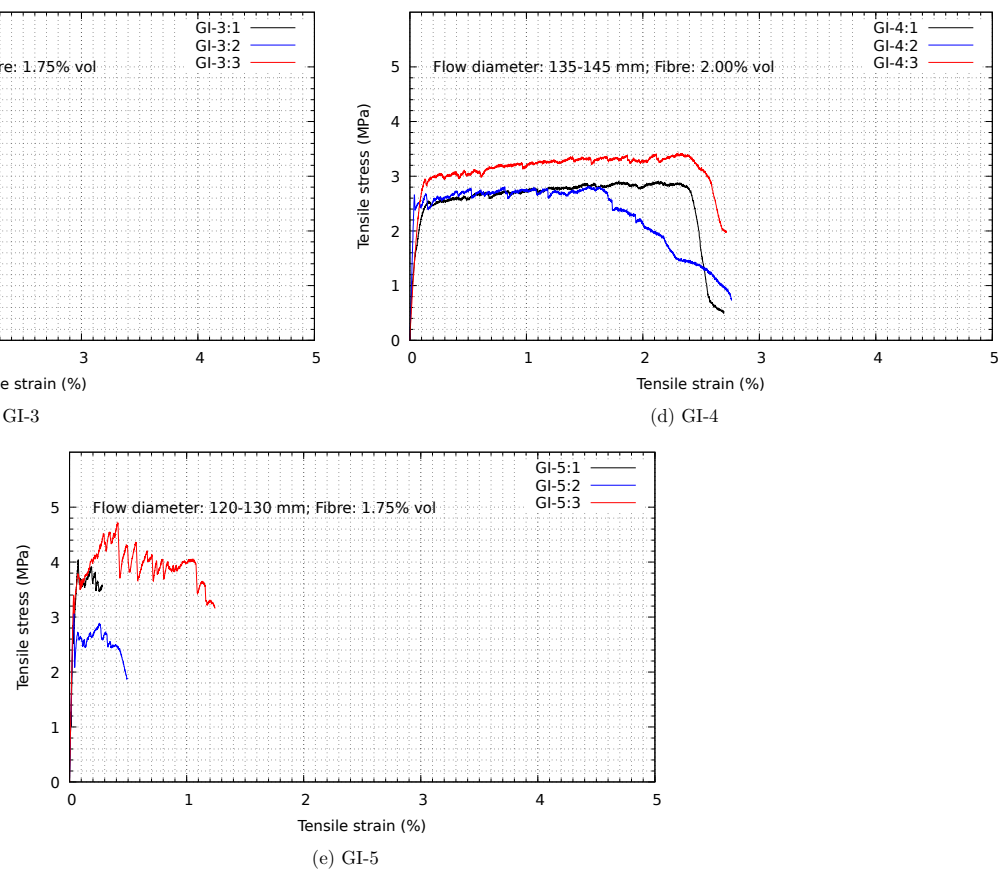

Figure 5: Results of tensile test of the lightweight composite of GI. 

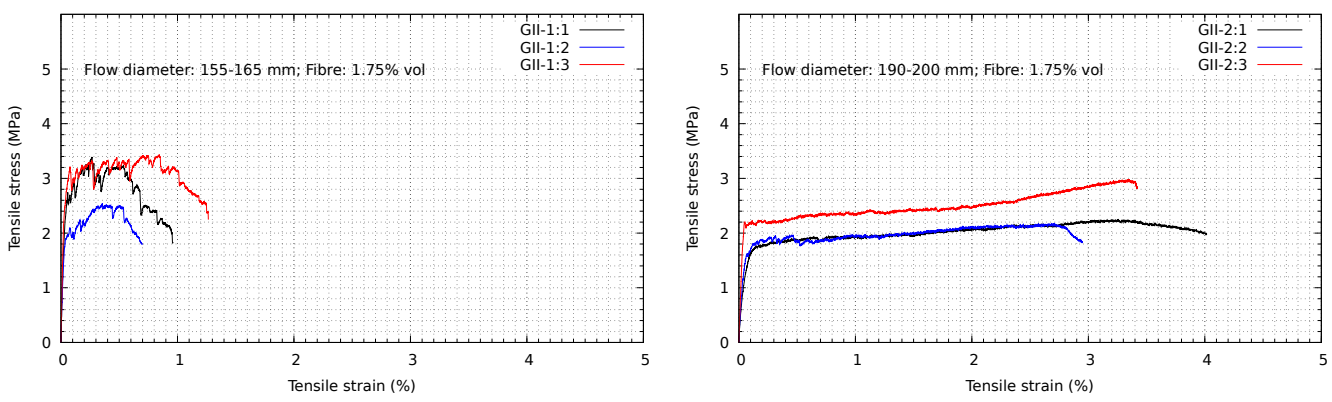

(a) GII-1

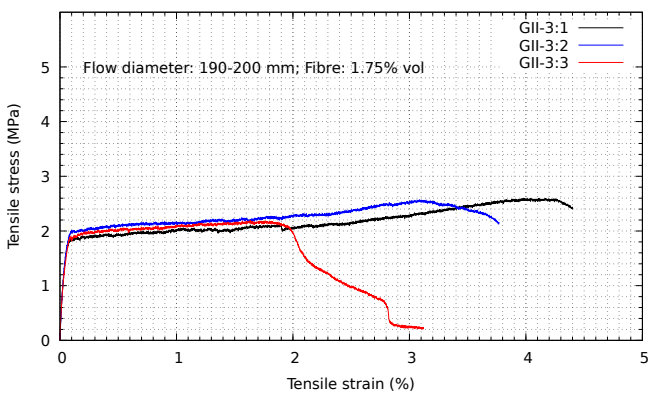

(b) GII-2

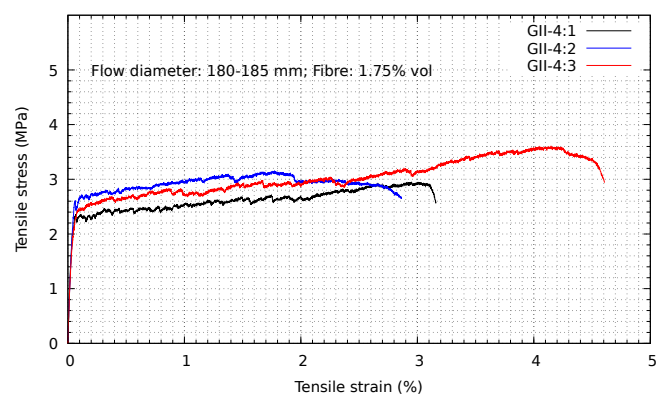

(c) GII-3
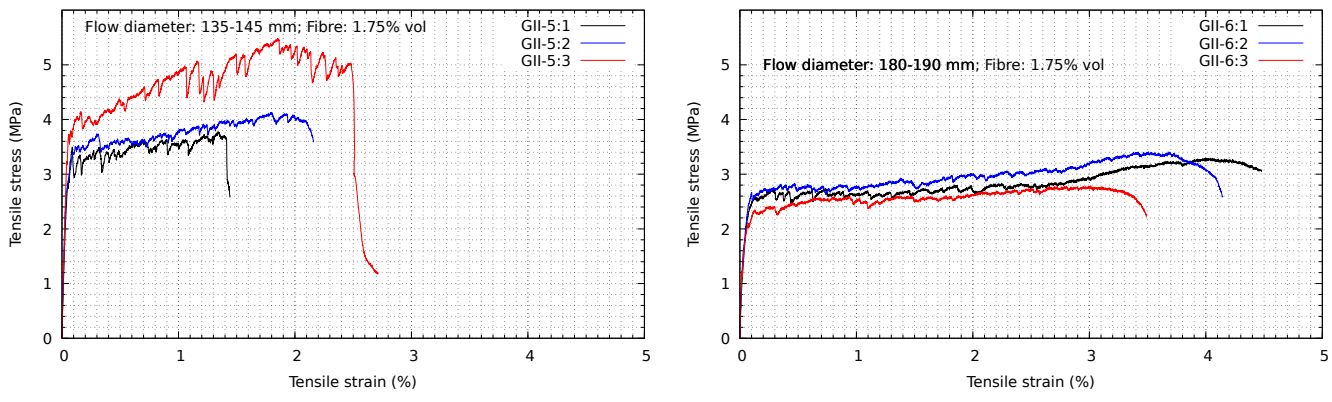

(e) GII-5

(f) GII-6

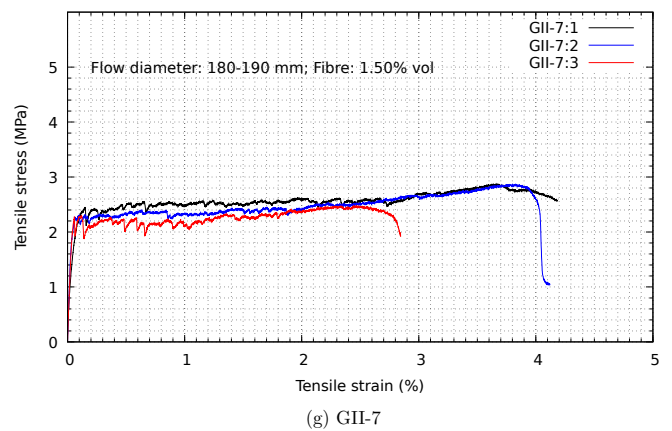

Figure 6: Results of tensile test of the lightweight composite of GII. 

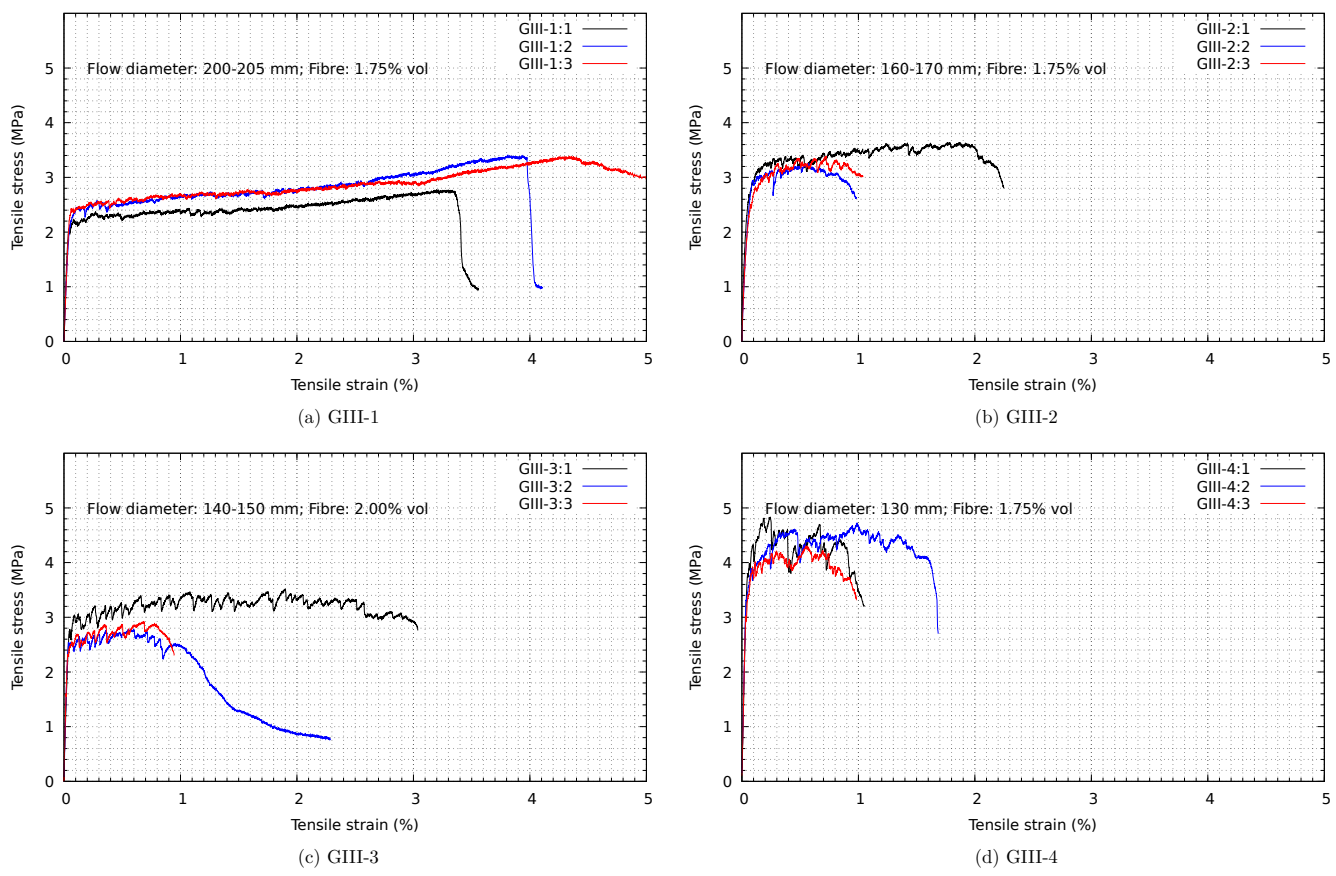

Figure 7: Results of tensile test of the lightweight composite of GIII. 


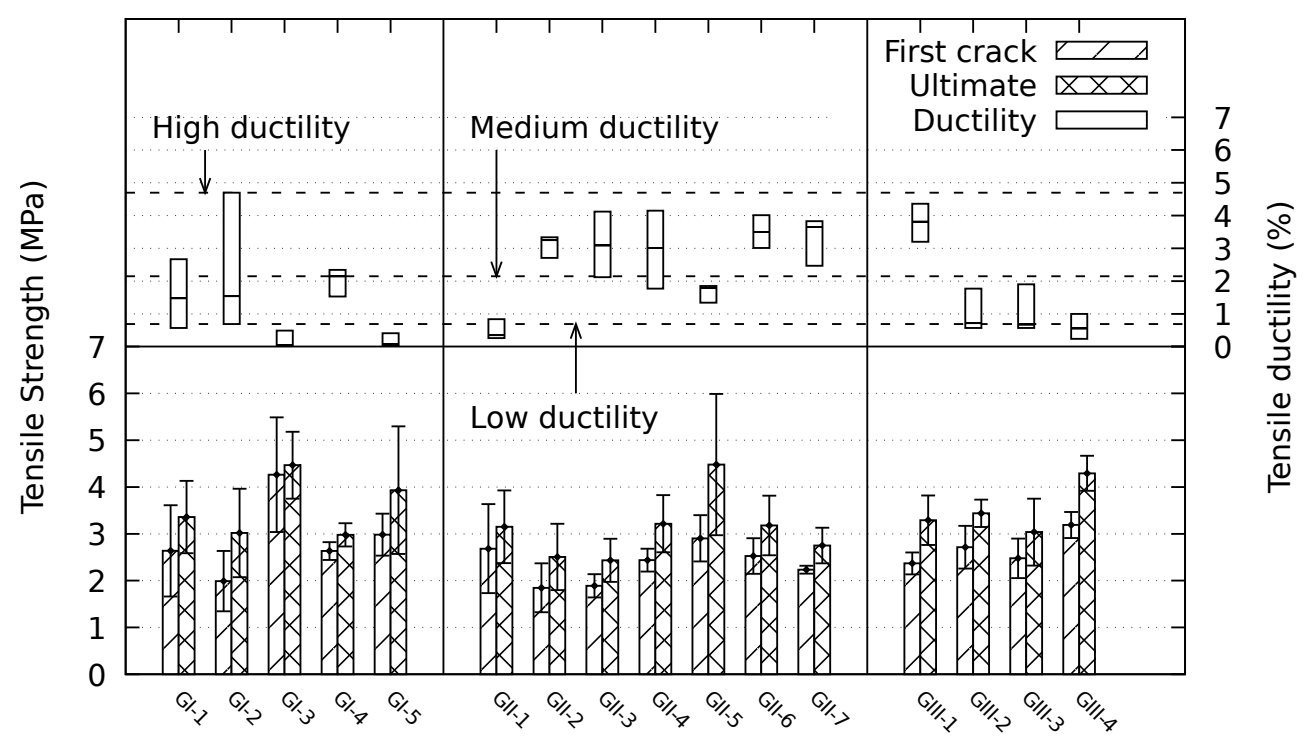

Figure 8: First crack strength, ultimate tensile strength and tensile ductility. 


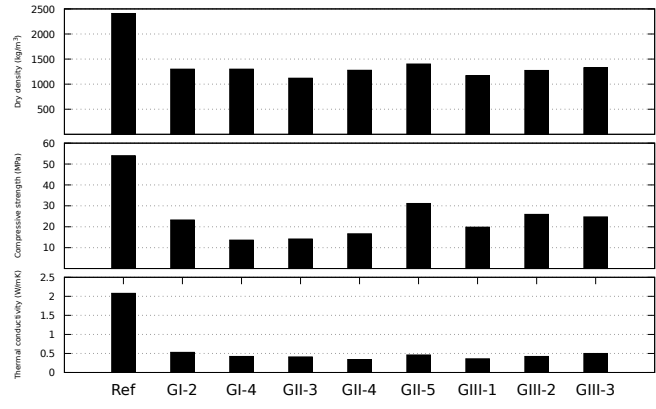

(a)

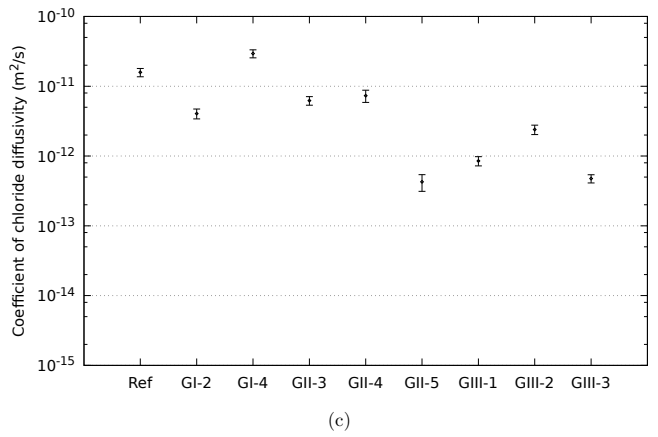

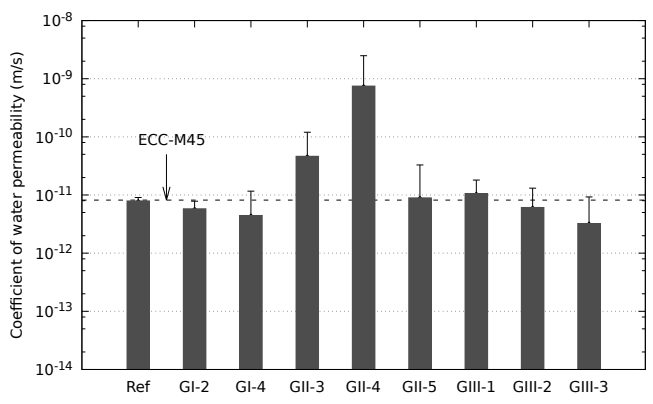

(b)

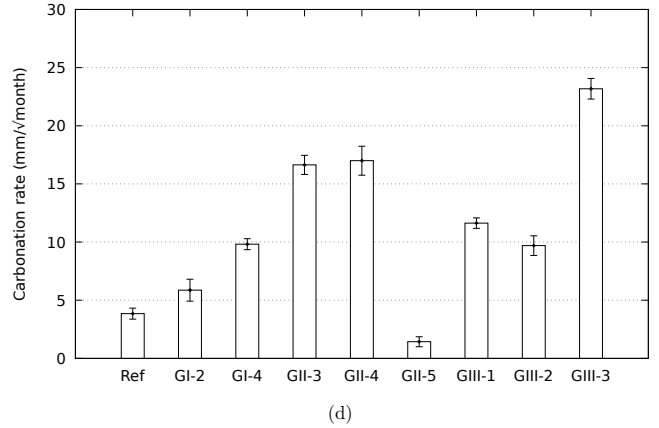

Figure 9: Results of (a) compression test, (b) thermal conductivity, (c) water permeability, (d) chloride diffusivity and (e) carbonation rate. 


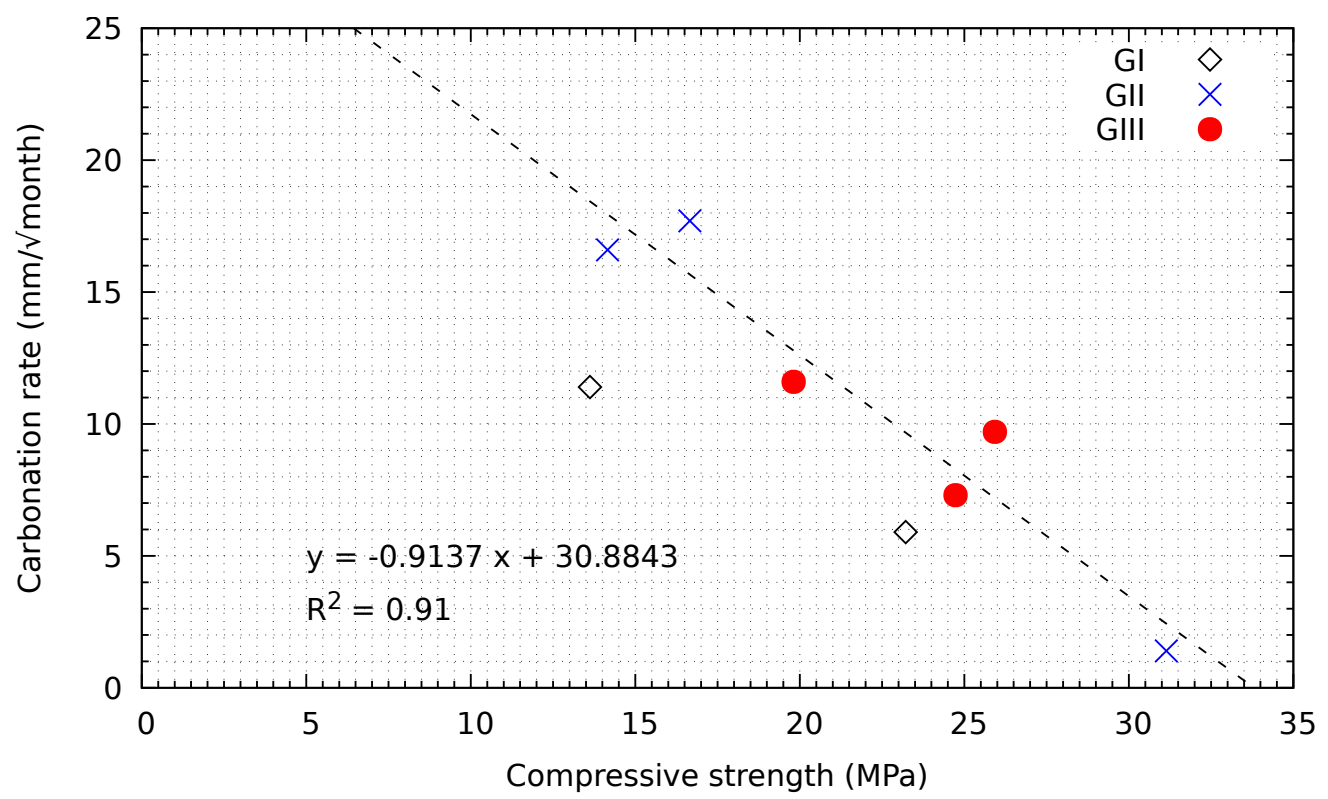

Figure 10: Relationship between carbonation rate and compressive strength of LSHCC. (The best-fitted line is only from the data of GII and GIII only.) 


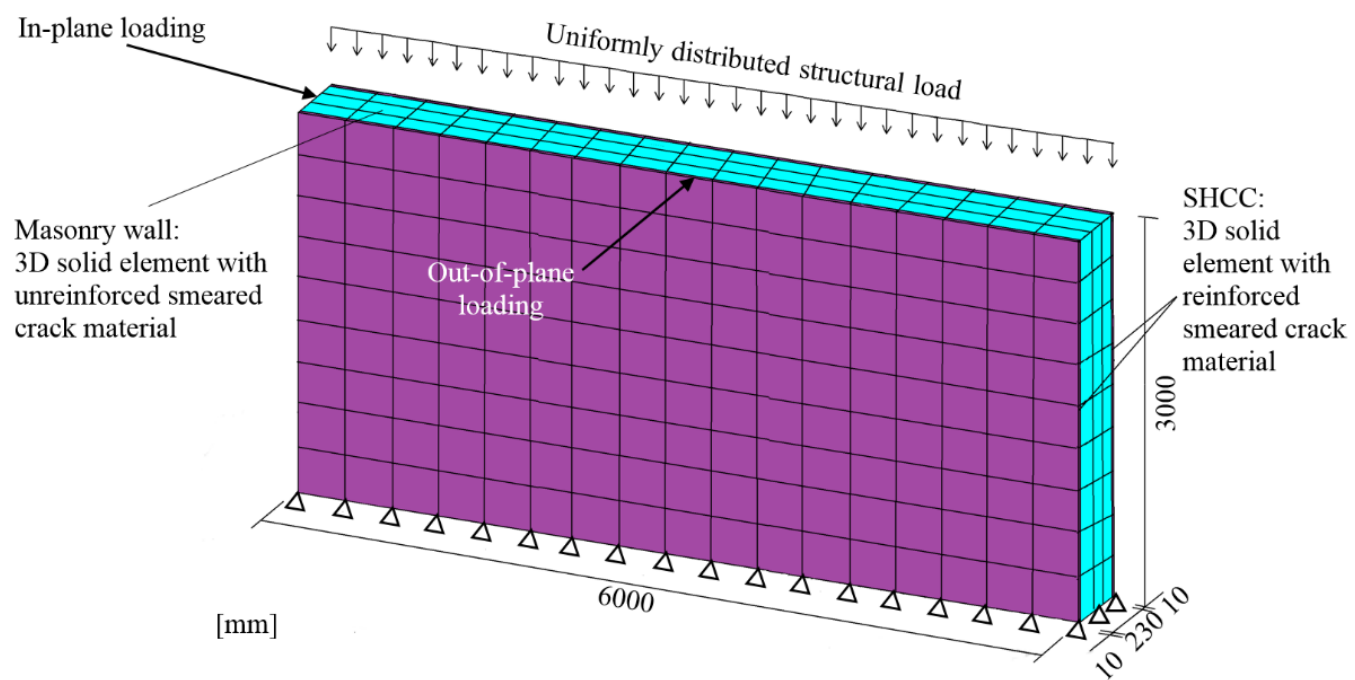

Figure 11: Three dimensional model of the pushover analysis. 


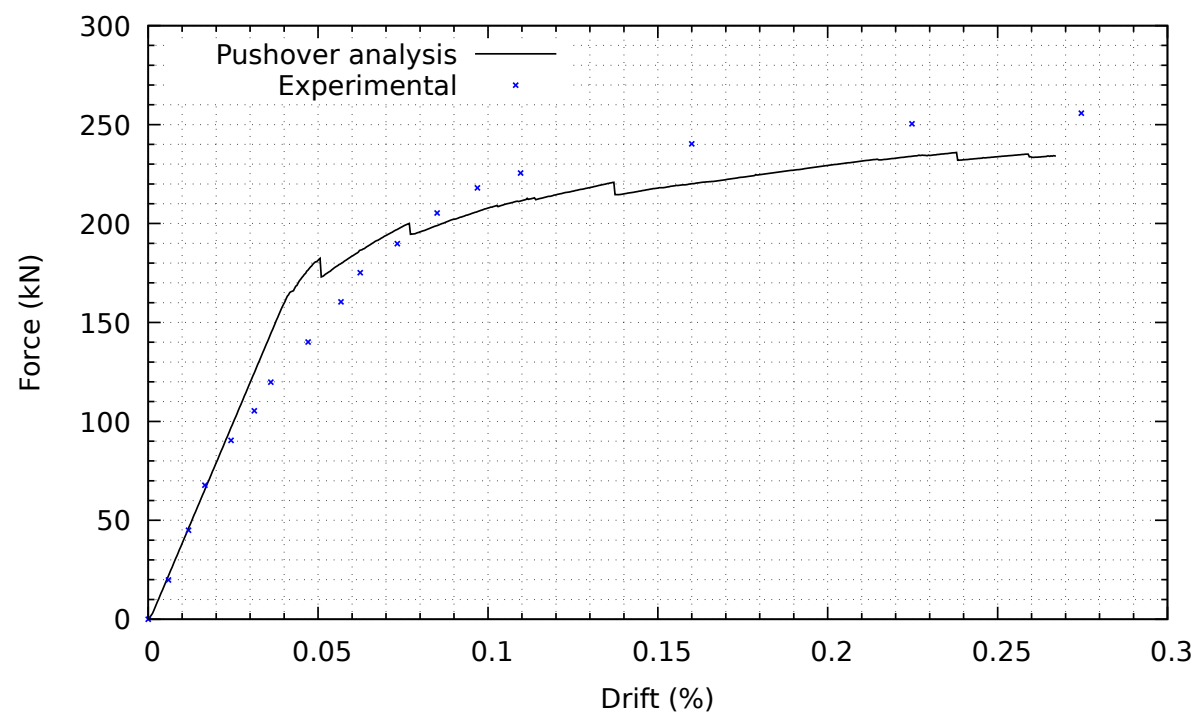

(a)

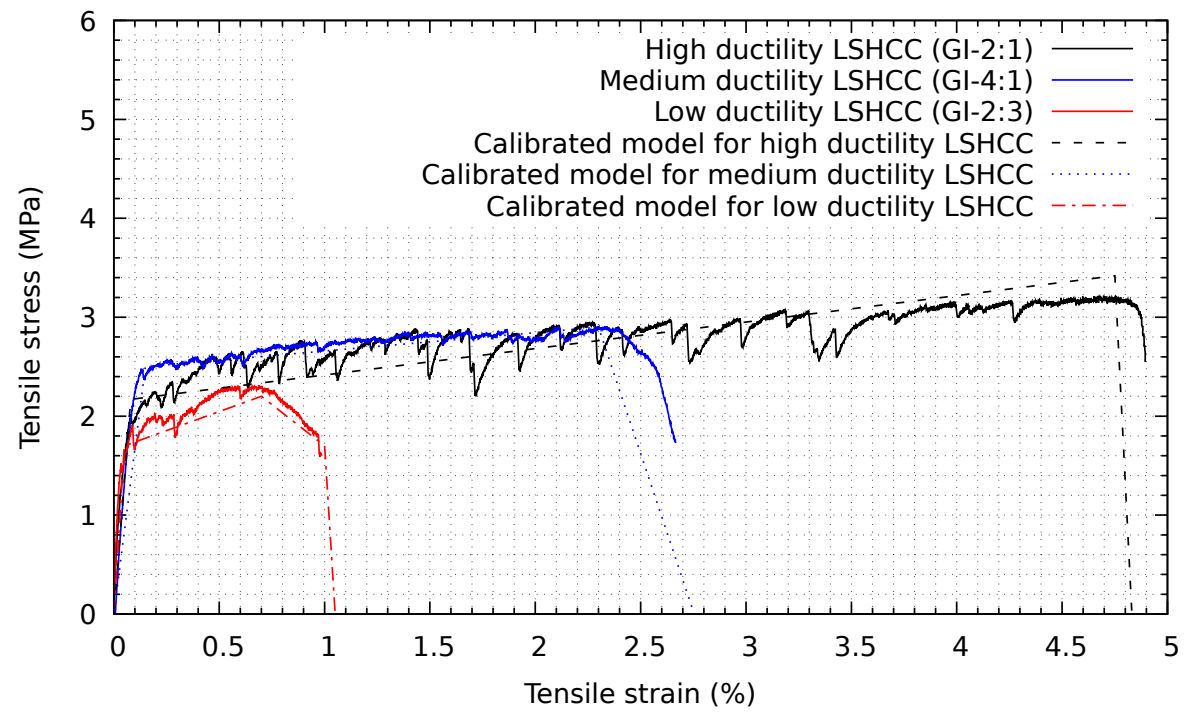

(b)

Figure 12: Model validation: (a) Masonry wall; (b) LSHCC.. 


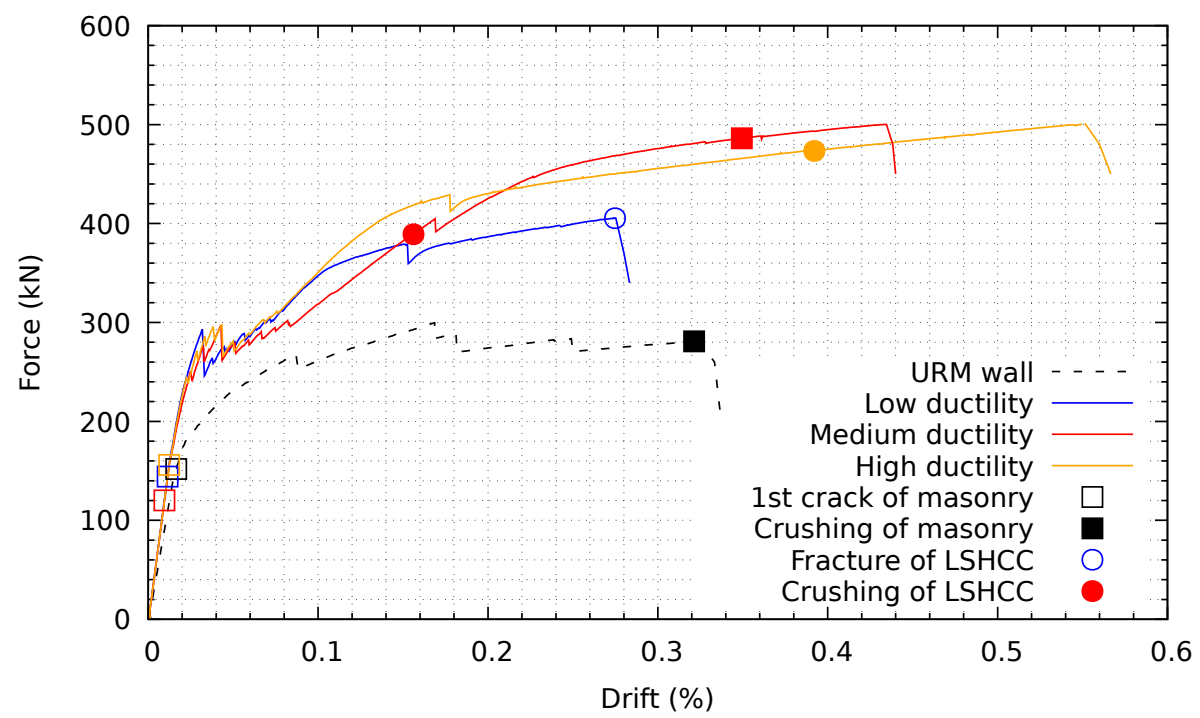

(a)

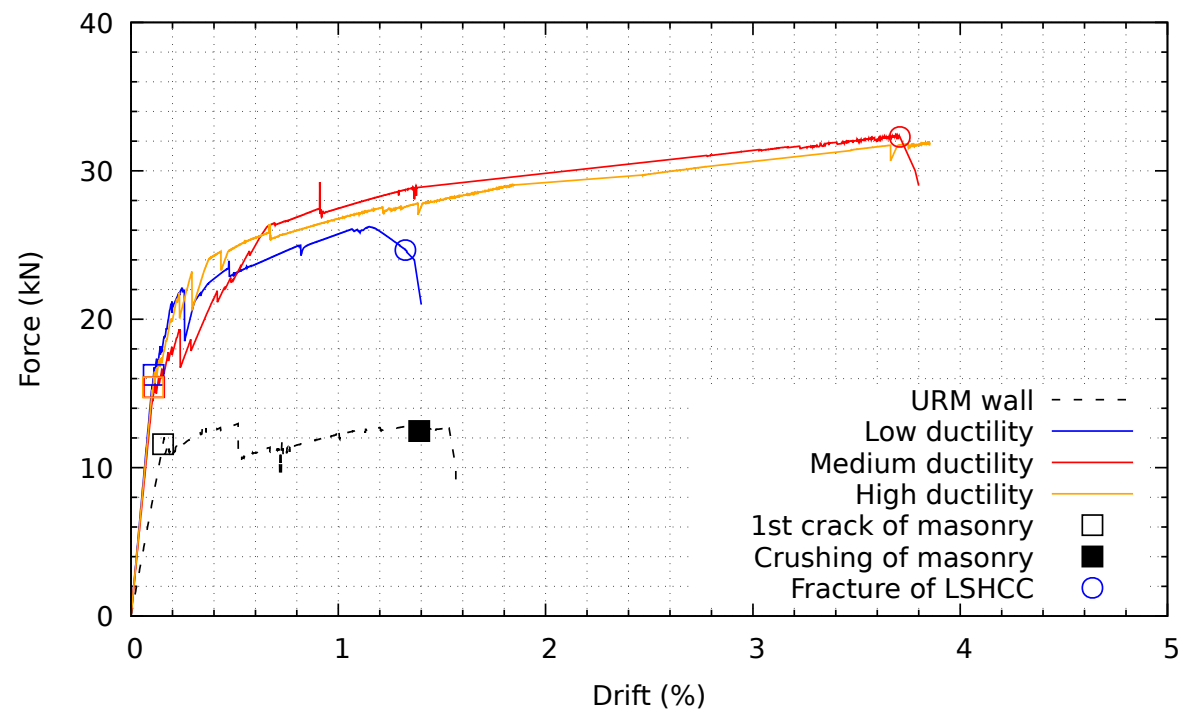

(b)

Figure 13: Base shear versus drift at the top of the wall: (a) In-plane; (b) Out-of-plane. 


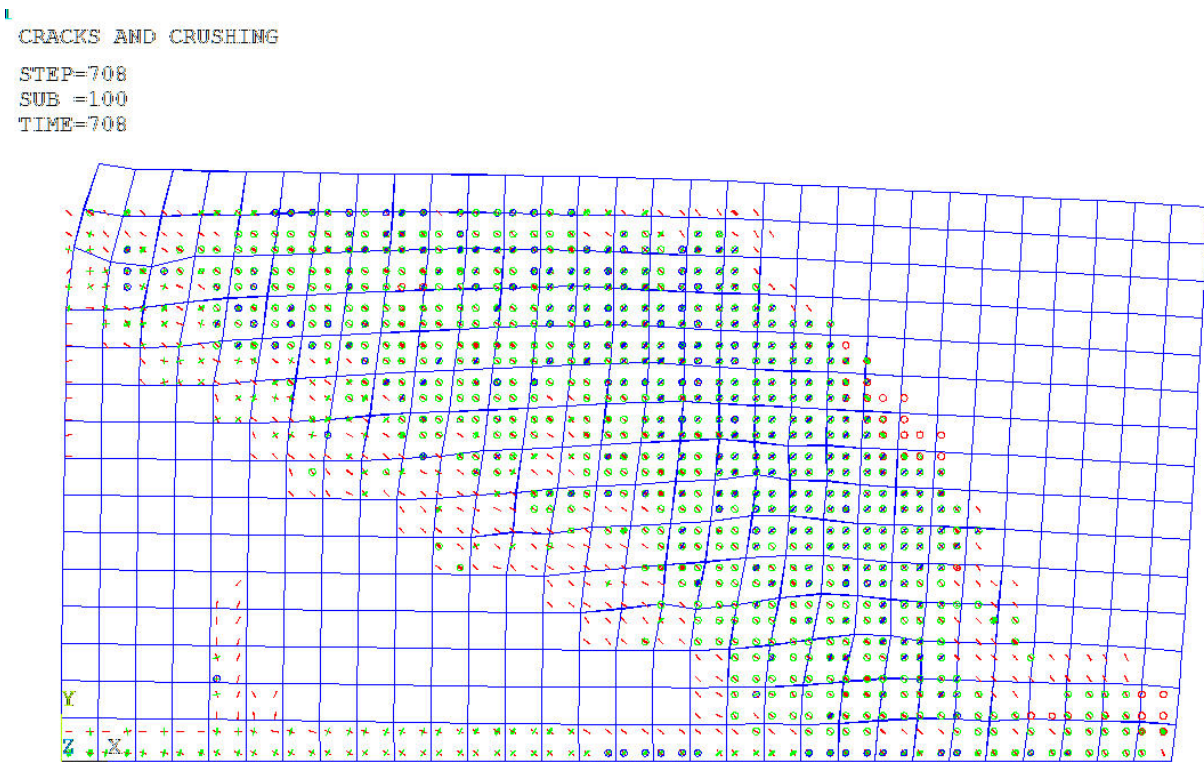

(a)

CRACKS AME CRUSHTHG

STT $\mathrm{P}=769$
SUE $=1$
TINWE $=769$

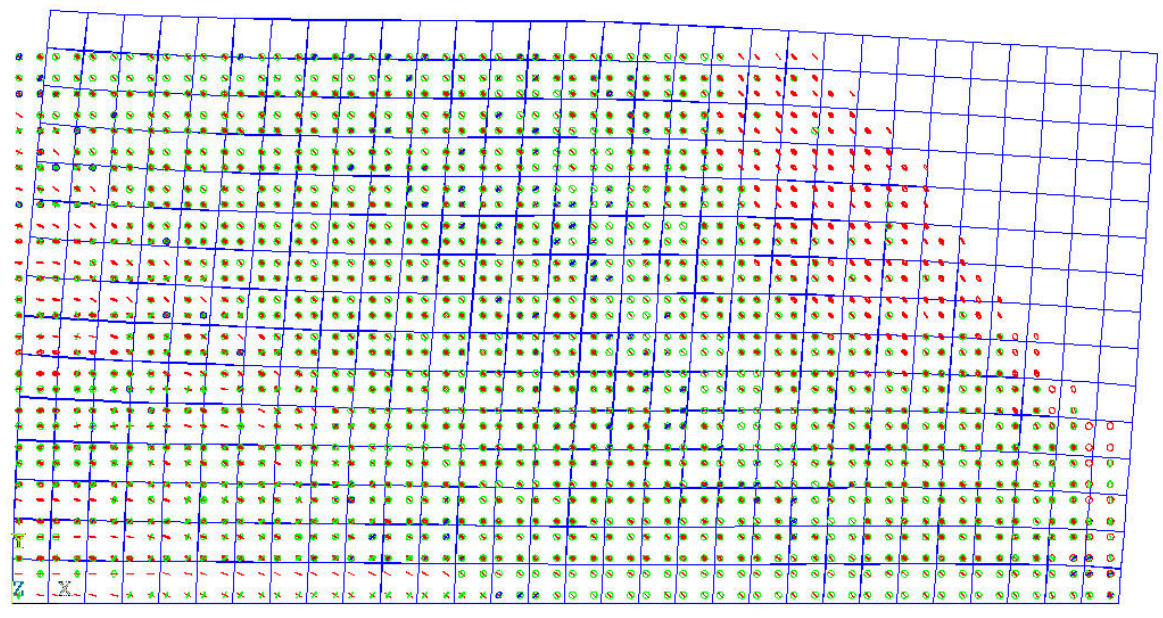

(b)

Figure 14: Crack patterns in the masonry wall element at $0.3 \%$ drift: (a) wall without LSHCC; (b) wall with medium ductility LSHCC 


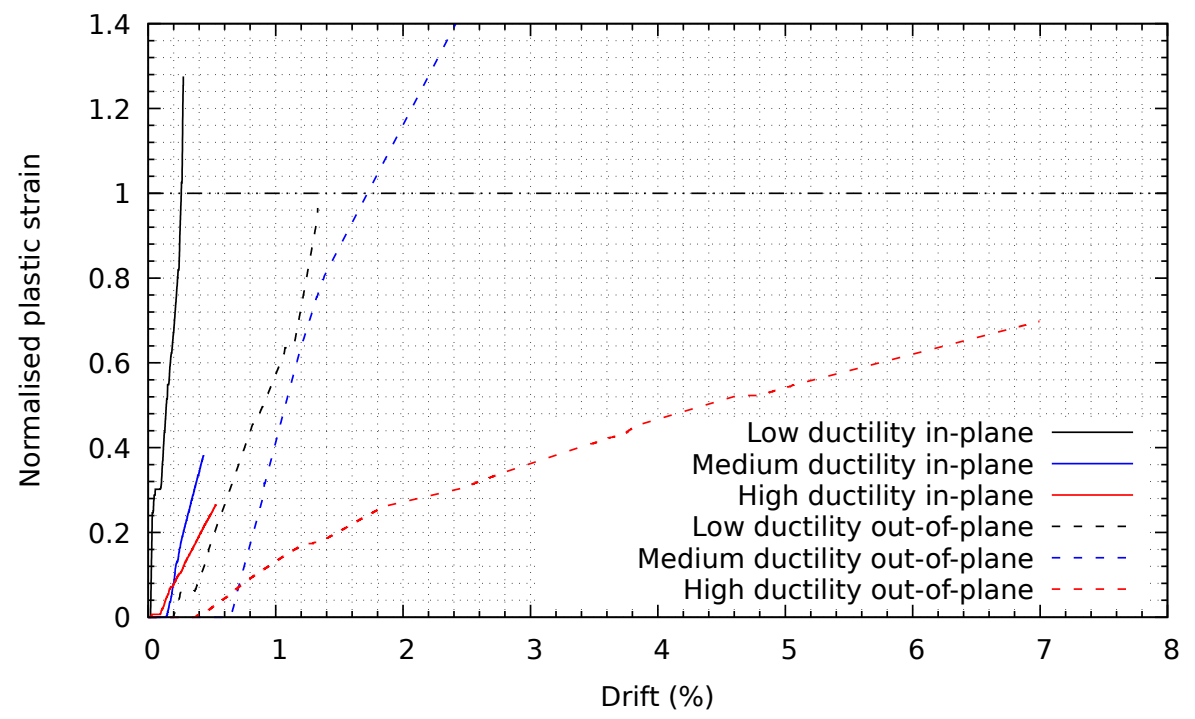

(a)

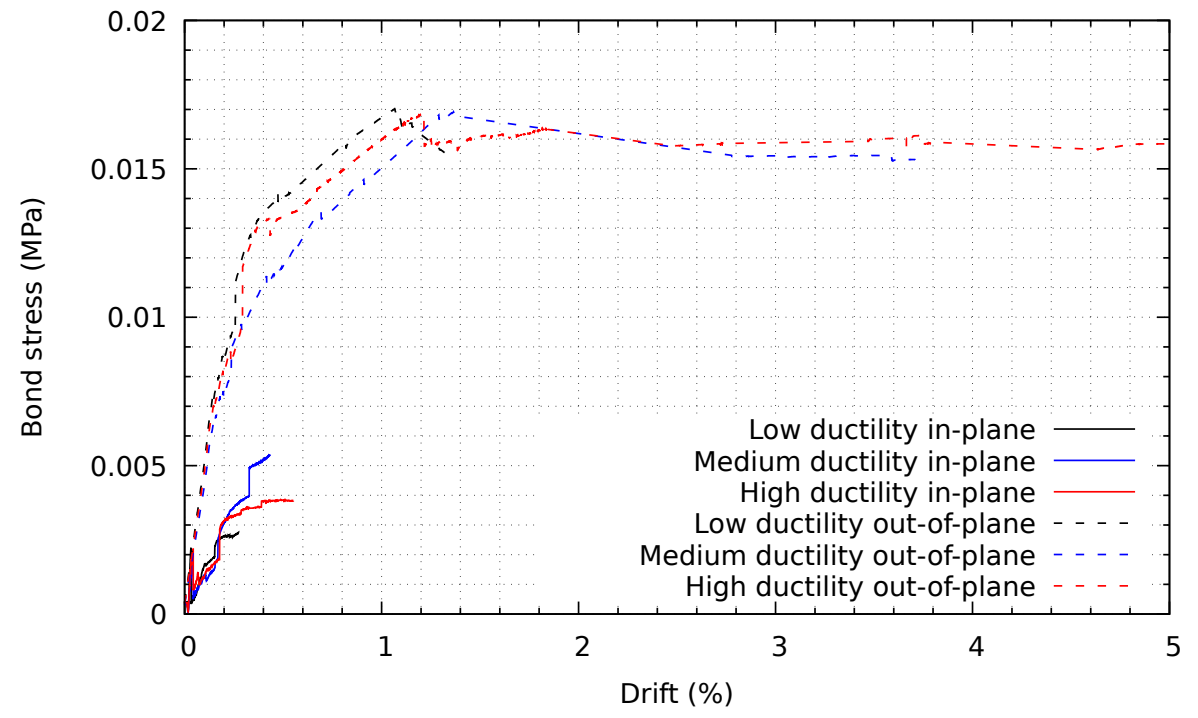

(b)

Figure 15: LSHCC response: (a) normalized plastic strain; (b) bond stress in the interface. 
Table 1: Summary of raw materials, density, thermal conductivity of lightweight strain hardening composite.

\begin{tabular}{lcccc} 
& 3M-S38 & 3M-S60 & EG & MS \\
\hline Matrix & OPC & OPC & FAG & FAG \\
LWA-matrix wt $\%$ & 20 & 50 & 16 & 10 \\
Density $\left(\mathrm{kg} / \mathrm{m}^{3}\right)$ & 1,450 & 930 & 1,754 & 1,586 \\
Thermal conductivity $(\mathrm{W} / \mathrm{m} \cdot \mathrm{K})$ & $\mathrm{N} / \mathrm{A}$ & $\mathrm{N} / \mathrm{A}$ & $\sim 0.9$ & $\sim 1.1$ \\
Ultimate tensile strength $(\mathrm{MPa})$ & 4.31 & 2.85 & 3.8 & 3.4 \\
Tensile ductility $(\%)$ & 4.24 & 3.70 & 3.7 & 3.5
\end{tabular}

EG: expanded recycled glass

MS: microscopic hollow ceramic spheres

LWG: lightweight aggregates

FAG: fly ash based geopolymer 
Table 2: XRF results of the raw materials of the cementitious matrix (in weight \%).

\begin{tabular}{l|ccc} 
& OPC & FA & GGBS \\
\hline $\mathrm{SiO}_{2}$ & 19.4 & 52.0 & 32.2 \\
$\mathrm{CaO}$ & 67.0 & 4.7 & 46.5 \\
$\mathrm{Al}_{2} \mathrm{O}_{3}$ & 3.4 & 30.7 & 12.3 \\
$\mathrm{Fe}_{2} \mathrm{O}_{3}$ & 3.5 & 5.9 & 1.0 \\
$\mathrm{SO}_{4}$ & 5.1 & 1.5 & 3.1 \\
$\mathrm{MgO}$ & 1.0 & 1.6 & 4.1 \\
$\mathrm{TiO}_{2}$ & 0.2 & 2.3 & 0.6 \\
$\mathrm{MnO}$ & 0.2 & 0.1 & 0.2 \\
$\mathrm{~K}_{2} \mathrm{O}$ & 0.2 & 1.2 & -
\end{tabular}


Table 3: Properties of PVA fibre.

\begin{tabular}{cccccc} 
Diameter & Length & $\begin{array}{c}\text { Elastic } \\
\text { modulus } \\
(\mathrm{GPa})\end{array}$ & $\begin{array}{c}\text { Elongation } \\
(\mu \mathrm{m})\end{array}$ & $\begin{array}{c}\text { Nominal } \\
\text { strength } \\
(\mathrm{GPa})\end{array}$ & $\begin{array}{c}\text { Density } \\
\left(\mathrm{mg} / \mathrm{m}^{3}\right)\end{array}$ \\
\hline 39 & 12 & 41 & 6 & 1.6 & 1,300
\end{tabular}


Table 4: Properties of lightweight aggregates.

\begin{tabular}{lcccccc} 
& unit & S15 & S38* & S60* & EG $^{\sharp}$ & MS $^{\sharp}$ \\
\hline Typical true specific gravity & & 0.15 & 0.38 & 0.6 & 1.4 & 0.85 \\
Thermal conductivity & $(\mathrm{W} / \mathrm{m} \cdot \mathrm{K})$ & 0.055 & 0.127 & 0.200 & N/A & 0.1 \\
Particle size range & $(\mu \mathrm{m})$ & $25-90$ & $15-75$ & $15-55$ & $40-125$ & $38-125$ \\
Median particle size & $(\mu \mathrm{m})$ & 55 & 40 & 30 & N/A & N/A \\
Isostatic crush strength & $(\mathrm{MPa})$ & 2.1 & 27.6 & 68.9 & N/A & 45
\end{tabular}

* is the glass micro-hollow bubble used in [32]

\# is the expanded recycled glass and microscopic hollow ceramic spheres used in $[43]$ 
Table 5: Mix proportion of mortar test.

\begin{tabular}{|c|c|c|c|c|c|c|c|c|c|c|c|c|c|}
\hline Mix & $\mathrm{OPC}$ & Water & Sand & S15 & $\begin{array}{c}\text { HPMC } \\
(\%)\end{array}$ & $\begin{array}{l}\text { SP } \\
(\%)\end{array}$ & $\begin{array}{c}\text { Dry mix } \\
\text { (min) }\end{array}$ & $\begin{array}{l}\text { Dry mix } \\
\text { (speed) }\end{array}$ & $\begin{array}{l}\text { Wet mix } \\
\quad(\min )\end{array}$ & $\begin{array}{l}\text { Wet mix } \\
\text { (speed) }\end{array}$ & $\begin{array}{c}\text { Water } \\
\text { content } \\
\left(\mathrm{kg} / \mathrm{m}^{3}\right)\end{array}$ & $\begin{array}{c}\text { Estimated } \\
\text { density } \\
\left(\mathrm{kg} / \mathrm{m}^{3}\right)\end{array}$ & $\begin{array}{c}\text { Measured } \\
\text { density } \\
\left(\mathrm{kg} / \mathrm{m}^{3}\right)\end{array}$ \\
\hline A1 & 1 & 0.46 & 1 & 0.10 & 0.150 & 1.20 & 7 & 1 & 18 & 1 & 261 & 1,396 & 1,858 \\
\hline A2 & 1 & 0.46 & 1 & 0.10 & 0.150 & 1.20 & 7 & 1 & 8 & 2 & 261 & 1,396 & 1,924 \\
\hline A3 & 1 & 0.46 & 1 & 0.10 & 0.120 & 1.20 & 7 & 1 & 8 & 2 & 261 & 1,396 & 1,899 \\
\hline $\mathrm{A} 4$ & 1 & 0.46 & 1 & 0.10 & 0.120 & 1.00 & 7 & 1 & 18 & 1 & 261 & 1,396 & 1,858 \\
\hline A5 & 1 & 0.46 & 1 & 0.10 & 0.060 & 1.00 & 7 & 1 & 18 & 1 & 261 & 1,396 & 1,888 \\
\hline B1 & 1 & 0.50 & 1 & 0.10 & 0.225 & 1.70 & 7 & 1 & 14 & 1 & 278 & 1,388 & 1,604 \\
\hline B2 & 1 & 0.50 & 1 & 0.10 & 0.150 & 1.00 & 7 & 1 & 14 & 1 & 278 & 1,388 & 1,731 \\
\hline C1 & 1 & 0.55 & 1 & 0.10 & 0.188 & 1.00 & 7 & 1 & 10 & 1 & 297 & 1,377 & 1,487 \\
\hline $\mathrm{C} 2$ & 1 & 0.55 & 1 & 0.10 & 0.150 & 0.70 & 7 & 1 & 11 & 1 & 297 & 1,377 & 1,552 \\
\hline D1 & 1 & 0.60 & 1 & 0.10 & 0.188 & 0.63 & 7 & 1 & 9 & 1 & 316 & 1,368 & 1,417 \\
\hline D2 & 1 & 0.60 & 1 & 0.10 & 0.150 & 0.40 & 7 & 1 & 9 & 1 & 316 & 1,368 & 1,473 \\
\hline D3 & 1 & 0.60 & 1 & 0.10 & 0.113 & 0.30 & 7 & 1 & 9 & 1 & 316 & 1,368 & 1,523 \\
\hline D4 & 1 & 0.60 & 1 & 0.10 & 0.075 & 0.30 & 7 & 1 & 9 & 1 & 316 & 1,368 & 1,611 \\
\hline D5 & 1 & 0.61 & 1 & 0.10 & 0.150 & 0.20 & 7 & 1 & 10 & 1 & 316 & 1,366 & 1,728 \\
\hline D6 & 1 & 0.60 & 1 & 0.10 & 0.075 & 0.20 & 7 & 1 & 9 & 1 & 316 & 1,368 & 1,688 \\
\hline D7 & 1 & 0.60 & 1 & 0.10 & 0.000 & 0.20 & 7 & 1 & 8 & 1 & 316 & 1,368 & 1,623 \\
\hline D8 & 1 & 0.60 & 1 & 0.10 & 0.038 & 0.17 & 7 & 1 & 15 & 1 & 316 & 1,368 & 1,801 \\
\hline D9 & 1 & 0.60 & 1 & 0.10 & 0.000 & 0.15 & 7 & 1 & 13 & 1 & 316 & 1,368 & 1,747 \\
\hline D10 & 1 & 0.60 & 1 & 0.10 & 0.075 & 0.10 & 7 & 1 & 15 & 1 & 316 & 1,368 & 1,895 \\
\hline D11 & 1 & 0.60 & 1 & 0.10 & 0.000 & 0.10 & 7 & 1 & 18 & 1 & 316 & 1,368 & 1,861 \\
\hline E1 & 1 & 0.61 & 1 & 0.10 & 0.150 & 0.20 & 7 & 1 & 10 & 1 & 319 & 1,366 & 1,728 \\
\hline F1 & 1 & 0.71 & 1 & 0.10 & 0.150 & 0.15 & 7 & 1 & 10 & 1 & 353 & 1,349 & 1,584 \\
\hline
\end{tabular}


Table 6: Mix proportion of direct tensile test.

\begin{tabular}{|c|c|c|c|c|c|c|c|c|c|c|c|c|c|c|c|c|}
\hline Mix & Mix & $\mathrm{OPC}$ & $\mathrm{FA}$ & GGBS & Water & Sand & S15 & $\begin{array}{c}\text { HPMC } \\
\qquad \%\end{array}$ & SP & $\begin{array}{c}\text { Fibre } \\
(\% \mathrm{vol})\end{array}$ & $\begin{array}{c}\text { Water } \\
\text { content } \\
\left(\mathrm{kg} / \mathrm{m}^{3}\right)\end{array}$ & $\begin{array}{l}\text { Estimated } \\
\text { density } \\
\left(\mathrm{kg} / \mathrm{m}^{3}\right)\end{array}$ & $\begin{array}{c}\text { Measured } \\
\text { density } \\
\left(\mathrm{kg} / \mathrm{m}^{3}\right)\end{array}$ & $\begin{array}{c}\text { Error } \\
\%\end{array}$ & $\begin{array}{c}\text { Dry } \\
\text { density } \\
\left(\mathrm{kg} / \mathrm{m}^{3}\right)\end{array}$ & $\begin{array}{c}\text { Flowability } \\
(\mathrm{mm})\end{array}$ \\
\hline 48 & GI-1 & 1 & - & - & 0.35 & - & 0.057 & 0.11 & 1.00 & 2.00 & 331 & 1,255 & 1,252 & -0.2 & 1,245 & $160-170$ \\
\hline 54 & GI-2* & 1 & - & & 0.4 & 0.165 & 0.060 & 0.15 & 1.00 & 2.00 & 327 & 1,378 & 1,309 & -5.0 & 1,300 & $140-150$ \\
\hline 35 & GI-3 & 1 & - & - & 0.375 & 0.165 & 0.065 & 0.12 & 1.20 & 1.75 & 304 & 1,345 & 1,420 & 5.6 & 1,350 & $120-130$ \\
\hline 51 & GI- $4^{*}$ & 1 & - & - & 0.47 & 0.500 & 0.080 & 0.11 & 1.50 & 2.00 & 300 & 1,360 & 1,338 & -1.6 & 1,300 & $136-145$ \\
\hline 23 & GI-5 & 1 & - & - & 0.35 & 0.165 & 0.065 & 0.15 & 1.50 & 1.75 & 290 & 1,364 & 1,415 & 3.7 & 1,392 & $120-130$ \\
\hline 5 & GII-1 & 0.5 & 0.5 & - & 0.325 & - & 0.050 & 0.094 & 0.45 & 1.75 & 306 & 1,3 & 1,3 & 4.3 & 1,309 & 160 \\
\hline 30 & GII-2 & 0.2 & 0.8 & - & 0.375 & 0.165 & 0.050 & 0.11 & 0.70 & 1.75 & 309 & 1,3 & 1,297 & -3.9 & 1,133 & $190-200$ \\
\hline 31 & GII- $3^{*}$ & 0.2 & 0.8 & - & 0.375 & 0.165 & 0.050 & 0.11 & 0.40 & 1.75 & 310 & 1,346 & 1,280 & -4.9 & 1,119 & $190-200$ \\
\hline 17 & GII- $4^{*}$ & 0.2 & 0.8 & - & & 0.165 & 0.050 & 0.11 & 0.70 & 1.75 & & & & 1.7 & 1,277 & $180-185$ \\
\hline 11 & GII- $5^{*}$ & 0.67 & 0.33 & - & 0.35 & 0.165 & 0.060 & 0.11 & 0.80 & 1.75 & 29 & & 1 & 6.1 & 1,401 & 140 \\
\hline 26 & GII-6 & 0.2 & 0.8 & - & 0.325 & 0.165 & 0.050 & 0.11 & 1.25 & 1.75 & 278 & 1,369 & 1,373 & 0.3 & 1,241 & $180-190$ \\
\hline 32 & GII-7 & 0.2 & 0.8 & - & 0.325 & 0.165 & 0.050 & 0.11 & 1.00 & 1.50 & 280 & 1,366 & 1,354 & -0.9 & 1,233 & 180-190 \\
\hline 41 & GIII-1* & 0.2 & 0.6 & 0.2 & 0.375 & 0.165 & 0.052 & 0.11 & 0.40 & 1.75 & 311 & 1,354 & 1,266 & -6.5 & 1,169 & $200-205$ \\
\hline 39 & III- $2^{*}$ & 0.2 & 0. & 0. & 0.375 & 0.165 & 0.060 & 0.1 & 0. & 1.75 & 307 & & & 0.7 & 1,274 & $160-170$ \\
\hline 52 & III-3* & 0.5 & 0.25 & 0.25 & 0.375 & 0.165 & 0.055 & 0.1 & 0.76 & 2.00 & & & & -2.9 & 1,328 & $140-150$ \\
\hline 42 & GIII-4 & 0.5 & - & 0.5 & 0.375 & 0.165 & 0.052 & 0.11 & 0.80 & 1.75 & 311 & 1,355 & 1,457 & 7.5 & 1,356 & 130 \\
\hline
\end{tabular}

\section{*: transport properties were measured.}


Table 7: Material properties of masonry wall model.

Elastic modulus Poissons ratio Uniaxial crushing stress Uniaxial cracking stress

\begin{tabular}{cccc}
$(\mathrm{MPa})$ & & $(\mathrm{MPa})$ & $(\mathrm{MPa})$ \\
\hline 2460 & 0.18 & 7.61 & 0.28
\end{tabular}

